\title{
Resale and Rent-Seeking: An Application to Ticket Markets
}

\author{
PHILLIP LESLIE \\ NBER and Anderson School of Management, UCLA \\ and \\ ALAN SORENSEN \\ NBER and Department of Economics, University of Wisconsin, Madison
}

First version received October 2009; final version accepted July 2013 (Eds.)

\begin{abstract}
We estimate an equilibrium model of ticket resale in which consumers' and brokers' decisions in the primary market reflect rational expectations about the resale market. Estimation is based on a unique dataset that merges transaction details from both the primary and secondary markets for tickets to major rock concerts. In our model, the presence of a resale market permits tickets to be traded from low-value to high-value consumers, but it also stimulates costly efforts by consumers and brokers to obtain underpriced tickets in the primary market. We estimate that observed levels of resale increase allocative efficiency by $5 \%$ on average, but that a third of this increase is offset by increases in costly rent-seeking in the primary market and transaction costs in the resale market.
\end{abstract}

Key words: Resale, Rent-seeking, Brokers, Ticket pricing.

JEL Codes: L82

\section{INTRODUCTION}

Many consumer goods and many productive assets are traded actively in both primary markets and secondary markets. In the primary market, an initial allocation of the good or asset is generated by means of an auction (e.g. treasury bonds), by transactions at posted prices (e.g. event tickets), or by some other non-market mechanism such as a government-run lottery (e.g. taxi licenses) 11 The resale market then generates a reallocation and redistribution of surplus. Naturally, the primary and secondary markets are highly interdependent: buyers' decisions in the primary market depend on their expectations about the resale market, and resale market outcomes depend on the nature of the primary market allocation. In this research we show that when the primary market is inefficient, the presence of resale opportunities may stimulate rent-seeking behaviour and transaction costs which reduce (and may undo) the allocative efficiency gains from having a secondary market.

The conventional view in economics is that resale is welfare-enhancing, because voluntary trading leads to more efficient allocations 2 The textbook explanation is that low-value buyers

1. See Che et al. (2013) for an analysis of resale following an initial lottery allocation.

2. See Happel and Jennings (1995); Hassett (2008); McCloskey (1985); Mankiw (2007); and Williams (1994). 
who purchased the good in the primary market can sell it to higher-value buyers in the secondary market at prices that make both buyer and seller better off. Regulations or frictions that interfere with such transactions would therefore decrease total surplus. The clear policy implication is that resale markets should be encouraged.

In practice, however, resale markets are often controversial. Ticket resale, which is the focus of this article, is the most salient example. In many jurisdictions (indeed in many countries) it is regulated or banned, and even where it is legal it is often stigmatized. Whether labelled as brokers, scalpers, or touts, ticket resellers tend to be loathed by concert artists, sports teams, and consumers. Roth (2007) even includes ticket scalping as an example of a "repugnant transaction". The widespread hostility towards ticket resale seems at odds with the view that voluntary trades made in resale markets are welfare-enhancing.

This article proposes and analyses a more nuanced model of resale markets that rationalises these divergent views. The textbook logic correctly suggests that, when there is an inefficient allocation in the primary market, resale markets increase welfare by reallocating goods from lowvalue buyers to high-value buyers. However, these welfare gains from reallocation may come at a cost. First, the resale transactions themselves may be costly. In the case of event tickets, sellers must advertise the availability of their tickets, find a buyer for the tickets, and then potentially incur shipping or other coordination costs to deliver the tickets to the buyer. Second, in settings where resale is driven by arbitrage, agents may engage in costly rent-seeking behaviour in the primary market, as would-be resellers compete for the expected resale profits. In ticket markets, the costly rent-seeking typically takes the form of brokers investing in strategies to buy up event tickets quickly when they go on sale, either by clogging phone lines and internet sites or by paying "pullers" to be first in line at the box office. Resale can thus stimulate socially inefficient behaviour in the primary market while simultaneously promoting efficient reallocations in the secondary market 3 Indeed, we show that resale markets may generate rent-seeking costs that more than offset the welfare gains from reallocation.

We develop a structural econometric model of the market for event tickets and use it to measure the welfare consequences of resale. The model allows us to compare equilibrium outcomes when there is active resale versus equilibrium outcomes in the absence of resale. This is necessary because the gains from reallocation in the resale market are not simply the difference in welfare between the final allocation (after resale) and the initial allocation (after the primary market). Rather, the reallocative gain is the difference between the final allocation after resale, and the allocation that would have arisen in the primary market if resale were prohibited (and buyers knew this in advance).

In our analysis, a buyer is characterized by her willingness to pay (WTP) for ticket quality and by how costly it is for her to "arrive early" in the primary market (which, for simplicity, we can think of as her cost of waiting in line). Using the standard definition of allocative efficiency, an allocation of tickets is efficient if the highest-WTP buyer gets the highest-quality ticket, the second highest-WTP buyer gets the second highest-quality ticket, and so on. In our model each buyer optimally chooses how much costly effort to put towards purchasing a ticket in the primary market. This effort choice depends on the buyer's WTP and her arrival cost, and also on the effort choices of other buyers. We model it as a strategic decision and compute a Nash equilibrium in which each buyer's effort choice is optimal given the effort choices of all other buyers. These effort choices in the primary market (and, hence, the allocation that emerges from the primary market) will also depend on whether there is a subsequent resale market.

3. Research into auctions with resale also identifies the potential for distortionary behaviour in the initial auction. See Haile (2001), (2003); Garratt and Tröger (2006), and Hafalir and Krishna (2008). 
The introduction of a resale market has several effects. First, resale markets make it easier for buyers with high WTP and high arrival costs to obtain tickets. This is the textbook reallocation effect. In essence, resale lowers the overall cost for these types of buyers. Second, resale stimulates competition for tickets in the primary market, as brokers and consumers vie to be first to obtain the high-quality seats. This effectively increases consumers' overall cost of buying tickets and reduces total welfare. Third, to the extent there are frictions in the secondary market, resale trades add transaction costs that further offset any welfare gains from reallocation. The structural model we develop in this article is designed to measure these different effects and determine the overall net effect of resale markets on consumer welfare.

Note that in order to evaluate the effect of resale markets on total welfare, one must make assumptions about the objective function of the primary market seller. As we discuss below, in the market for event tickets it is not obvious what the seller's objective is. Some sellers presumably aim to maximize profits-which, given the low marginal costs of selling an additional ticket, is roughly equivalent to maximizing revenue. However, some sellers may explicitly prefer that the tickets be used by low-WTP buyers. In that case, the reallocation achieved by the resale market may actually reverse the allocation desired by the seller, which would therefore represent a welfare loss to the seller. When we use our model to simulate the welfare effects of resale markets, we use revenue maximization as the benchmark objective for the primary market seller, and discuss how our conclusions about welfare would change under alternative assumptions about sellers' objectives.

Ticket markets are a useful testbed because they highlight the fundamental economics of resale and because they are particularly amenable to empirical analysis. Detailed, transaction-level data allow us to follow tickets through both the primary and secondary markets: we observe the price and quality of each ticket purchased in the primary market, whether each ticket was resold in the secondary market, and if it was resold we observe the resale price and whether the seller was a broker. The detailed data allow us to estimate the degree of heterogeneity in individuals' WTP and the level of transaction costs in the resale market, which are the key structural determinants of how resale markets function in practice. Ticket markets are also convenient because the good in question is perishable, and primary and secondary markets occur approximately in sequence over a short time frame (as we show below). This allows us to model the market with a relatively parsimonious stage game.

To our knowledge, ours is the first study of ticket resale to utilize transaction data from both the primary market and the resale market 4 Our sample covers transactions for 56 rock concerts, and the data reveal several interesting facts about resale markets for these events. While brokers accounted for the majority of resale activity, $46 \%$ of the resale transactions in our data were sold by non-brokers (i.e. consumers). On average, ticket prices in the resale market were $41 \%$ above face value. However, it was relatively common to see prices below face value: brokers (non-brokers) appeared to lose money on $21 \%(31 \%)$ of the tickets they sold. The overall rate of resale was relatively low during our sample period, with only $5 \%$ of purchased tickets being resold on eBay or StubHub. Of course, for certain events this number was much higher. The event in our dataset with the most active resale market had $17 \%$ of its tickets resold on eBay or StubHub, and resale market revenue on these sites was equal to $37 \%$ of the primary market revenue. The likelihood of resale was strongly associated with seat quality: the best tickets were roughly four times more likely to be resold than low- to mid-quality tickets. Importantly, the speed at which tickets sold

4. Prior empirical studies of ticket resale include Williams (1994); Elfenbein (2005); Depken (2007); Hassett (2008); and Sweeting (2012). Theoretical studies related to ticket resale include Thiel (1993); Courty (2003); Geng et al. (2007); and Karp and Perloff (2005). 
in the primary market accords well with the "arrival costs" aspect of our model: events for which resale profits were largest were the events for which the primary market tickets sold the fastest.

Based on the estimated structural model, we find that the observed levels of resale activity generate modest improvements in allocative efficiency relative to a world without resale. However, these improvements come at a significant cost. A third of the increase in gross surplus is offset by the combination of higher transaction costs in the resale market and higher rent-seeking costs in the primary market. Our estimates also imply that rent-seeking behaviour leads to primary market allocations that are significantly more efficient than a random allocation, as high-WTP consumers try hardest to obtain tickets in the primary market.

We estimate that consumers have large transaction costs, preventing many exchanges that would otherwise improve welfare. Our counterfactual analyses indicate that the participation of brokers, whose transaction costs are much lower, leads to a net welfare gain. In general, large reductions in transaction costs (for brokers and consumers) would lead to potentially significant increases in social efficiency. For example, we estimate that net social surplus (which we measure as sellers' revenues plus buyers' net surplus) would increase by $7 \%$ if resale markets were frictionless.

Even though we estimate that resale increases aggregate surplus, our estimates show that not everyone is made better off. Under frictionless resale, for example, there is a large increase in surplus captured by ticket resellers, but a large decrease in the surplus earned by concertgoers. In other words, while resale reallocates tickets in a way that increases aggregate surplus, ticket resellers capture more surplus than they create. The biggest losers from resale are the consumers who actually attend the event.

There are general lessons from this research. While our model and data are specific to the market for event tickets, our study illustrates several effects that apply to resale markets more broadly. Our results confirm that the gross welfare gains from reallocation can be large. However, our analysis also reveals that: (i) these gains are attenuated by non-trivial transaction costs in the resale market; (ii) resale is not pareto-improving - many of the buyers who consume the good in the final allocation are in fact worse off than if there was no resale; and (iii) the aggregate gains from reallocation spur a significant increase in costly rent-seeking activity by participants in the primary market which may, in practice, outweigh the welfare gains from reallocation.

The article proceeds as follows. In Section 2 we briefly outline the relevant institutional details about the market for concert tickets. In Section 3 we explain how we compiled the data and provide summary statistics and descriptive analyses. The model is outlined in Section 4, and the details of the estimation, including identification, are described in Section 5. Section 6 discusses the results of various counterfactual simulations designed to assess the welfare consequences of resale, and Section 7 concludes.

\section{MARKET OVERVIEW}

Live music and sporting events generate over $\$ 20$ billion in primary market ticket sales in the U.S. each year; resales of those tickets generate roughly $\$ 3$ billion (Mulpuru and Hult, 2008). An important distinction from other ticketed products, such as airline travel, is that event tickets are usually transferable, which is necessary for legitimate resale activity. Concerts are organized and financed by promoters, but the artists themselves are principally responsible for setting prices 5 Promoters employ ticketing agencies to handle the logistics of ticket selling. The dominant firm in this industry is Ticketmaster, which serves as the primary market vendor for over half of the major 
concerts in North America. Ticketmaster sells tickets primarily online or by phone. Tickets are delivered either as paper tickets by regular mail or as printable tickets by email. The secondary market uses these same delivery methods. Tickets usually go on sale three months before the event, and sometimes sell out on the first day.

Primary market pricing schemes tend to be strikingly simple, especially given the possibilities for price discrimination. Venues often have over 20,000 seats, with significant quality variation, implying many potential price-quality menus based on different partitions of the venue 6 Demand can be unpredictable, which has led to some experimentation with auctions in the primary market, and demand can vary considerably over time, which has led some sellers (especially sports teams) to experiment with dynamic pricing. But attempts at more sophisticated pricing schemes have been the exception, not the rule. For rock concerts, most events exhibit little (if any) price variation based on seat quality, and very rarely are ticket prices changed over time. The consensus in the industry is that primary market pricing is far from optimal. In the words of Ticketmaster CEO Nathan Hubbard: "We're not pricing at the intersection of supply and demand. The high priced seats are usually not priced high enough, and the low priced seats aren't usually low enough.'7

Figure 1 illustrates the lack of sophistication in primary market pricing using two example concerts from our dataset. The graphs show all of the ticket transactions for these concerts. The vertical axis represents price, and the horizontal axis represents seat quality, ordered from worst to best (we explain the measure of seat quality in more detail below). Consider the first panel, which shows the data for a Kenny Chesney concert performed in Tacoma, Washington. The horizontal lines (which are actually dots for each transaction) represent tickets that were sold in the primary market, at three different price points. The other dots and squares represent resales by non-brokers (i.e. consumers) and brokers, respectively 8 It is clear from Figure 1 that there is remarkably little price variation in the primary market. For the Kenny Chesney concert there are three price points for an event that has nearly 21,000 seats, and for the Dave Matthew's concert all 24,873 seats are sold at the same price in the primary market. In both cases, the observed price variation in the secondary market provides a stark contrast. These are typical examples in our dataset.

Underpricing in the primary market for rock concerts has long been recognized as a puzzling phenomenon, and various rationalizations have been proposed. Artists may want to ensure the event sells out, because they like playing to a full house or because doing so enhances the experience for consumers 9 If concert tickets are complementary to recorded music sales and other merchandise, artists may set low prices to boost sales of these complementary goods. Artists sometimes also cite a desire to be fair or assure access for all fans 10 However, none of these theories explains why the best seats in the venue are the most underpriced, as shown in Figure 11 The puzzle is not simply the low level of prices, but also the lack of price variation 11

We looked for patterns in our data that would indicate which of the many proposed rationalizations of primary market pricing makes most sense. We found that different artists

6. Rosen and Rosenfield (1997) provide a theoretical analysis of how to divide a venue and what prices to set. See Leslie (2004) for an empirical analysis of price-quality menus in event ticketing.

7. As quoted in Forbes, February 18, 2011.

8. In the next section we explain the data more fully.

9. See Becker (1991); Busch and Curry (2006); and DeSerpa and Faith (1996).

10. See Kahneman et al. (1986).

11. The artist may want consumers to buy tickets early in order to stimulate higher demand (because early buyers then advertise the concert to others). In our sample, however, events that sell out in the first day or so-which seemingly have no need to stimulate demand in this way_also implement near-uniform price structures. 

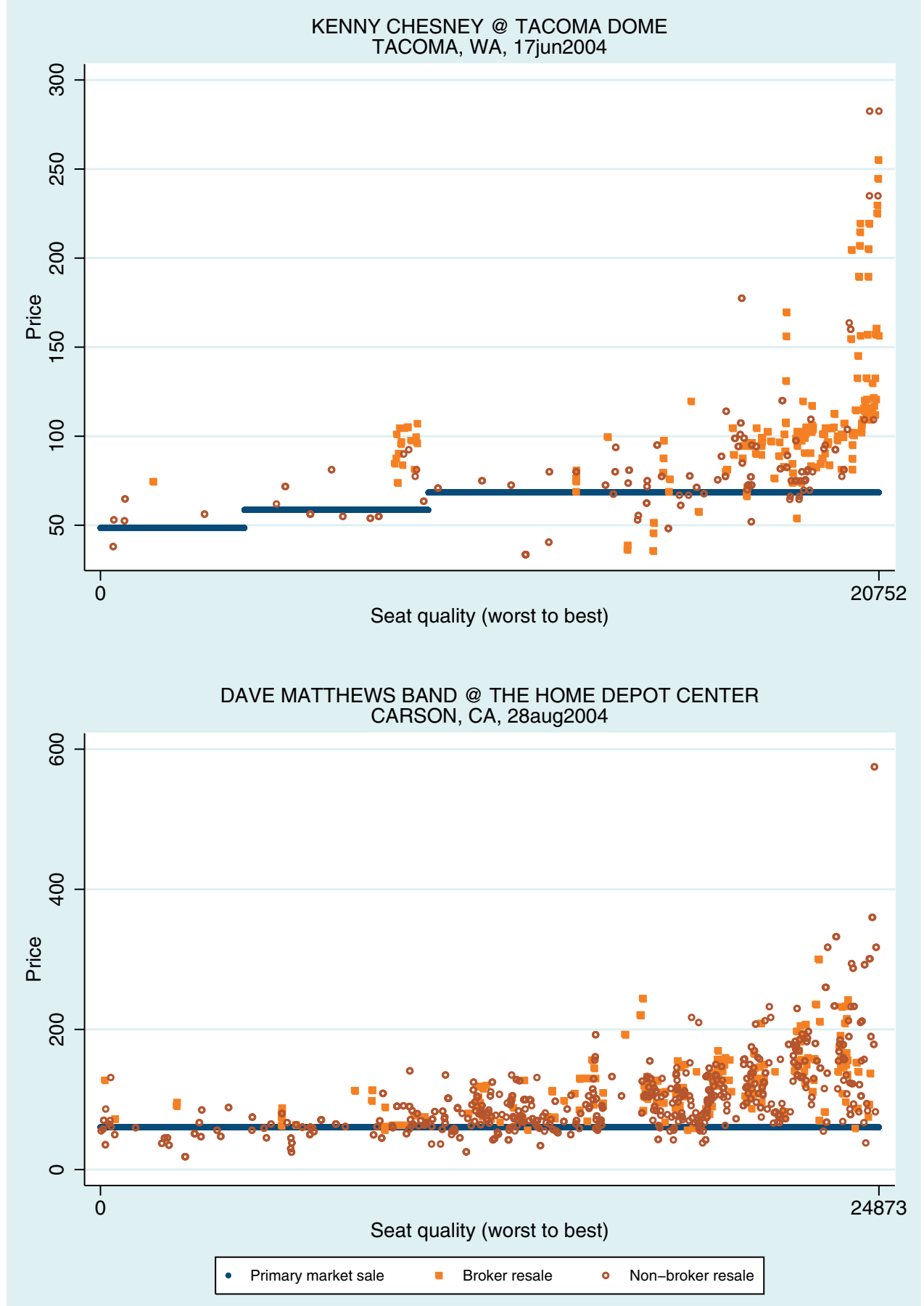

FIGURE 1

Two sample events 
appear to have consistently different policies about both the level of prices and the number of price tiers. There is some evidence that older artists (like Madonna) were more likely to price discriminate (i.e. use several price tiers), which would be consistent with a model in which dynamic considerations lead artists to leave more surplus to their fans early in their careers 12 Some venues appear to be more amenable to price discrimination than others, but we frequently observe different artists employing different pricing structures at the same venue. Overall, it seems that while revenue maximization may not be every artist's sole objective, our data cannot definitively identify which other objectives they might be pursuing, nor how much weight they put on these objectives. This ambiguity is not a problem for estimation as our approach does not require us to model primary market price-setting. However, when we analyze the welfare effects of resale in Section 6 we discuss how our conclusions might change if we assume artists care about more than just revenue maximization.

We study data from 2004, at which time eBay was the dominant marketplace for ticket resale, followed by StubHub 13 In one survey of concertgoers at a major rock concert in 2005, Krueger and Connolly (2005) found that eBay and StubHub accounted for between a third and a half of all resold tickets. In a separate survey from 2007, Mulpuru and Hult (2008) report that eBay and StubHub accounted for $55 \%$ of online ticket resales. To address fraud, eBay emphasizes their reputation mechanism, and StubHub provides a guarantee. Tickets are also resold on numerous other web sites (Razorgator, TicketsNow, TicketLiquidator, etc), as well as offline.

\section{DATA}

Our data combine detailed information about primary and secondary market sales for a sample of rock concerts performed during the summer of 2004. Our sample is not intended to be representative of the thousands of concerts performed that summer. Rather, it focuses on large concerts by major artists, for which resale markets tended to be most active.

From a research perspective, concerts are appealing for a number of reasons. As noted above, the available data are rich enough to make detailed quantitative analysis possible. Additionally, relative to other markets, concert ticket markets are relatively uncomplicated. All transactions in both the primary and secondary markets for a given concert take place in a well-defined time window (between the on-sale date the event date). Concerts are sufficiently differentiated that it is reasonable to ignore competition from other events. Also, tickets to multiple concert events are rarely bundled. This is not true of sports teams, which rely on season ticket buyers for a large portion of sales. Incorporating this aspect of ticket sales would add a layer of complexity for primary market demand and subsequent resale 14

\subsection{Primary market data}

The primary market data were provided by Ticketmaster. The sample includes 56 concerts performed by 12 different artists: Dave Matthews Band, Eric Clapton, Jimmy Buffett, Josh Groban, Kenny Chesney, Madonna, Phish, Prince, Rush, Sarah McLachlan, Shania Twain, and Sting. Since Ticketmaster is the sole primary market ticket seller for these event, we observe the universe of transactions in the primary market for these events. In total there were 1,034,353 tickets sold in the dataset. For each concert, we obtain information from two sources: a "seat

12. Courty and Pagliero (2012) report a similar finding in a much larger sample of events.

13. In January 2007, StubHub was acquired by eBay, and since then StubHub has become the dominant online marketplace for ticket resale.

14. See Chu et al. (2011) for an analysis of ticket bundling. 
map" and a daily sales audit. The seat maps list the available seats at a given event, indicating the order in which the seats were to be offered for sale, and the outcome (i.e. sold, comped, or open) 15 The daily audits contain ticket prices (including the various Ticketmaster fees), as well as how many tickets were sold in each price level on each day. The daily audits allow us to assign prices and dates of sale to the seats listed in the seat maps. The information on the timing of sales in the primary market is crucial for our analysis of the arrival game, detailed below.

We use the ordering of seats in the seat map data as our measure of relative seat quality. The main virtue of this approach is that it reflects the primary market vendor's assessment of quality: Ticketmaster uses this ordering to determine the current "best available" seat when a buyer makes an inquiry online or by phone. Also, it allows us to measure quality separately for each seat, as opposed to using a coarser measure (such as assigning qualities by section). The seat orderings are also fairly sophisticated. For example, seats in the middle of a row might be ranked above seats toward the outsides of rows further forward, and seats at the front of upper-level sections are sometimes ranked above seats at the back of lower-level sections.

Nevertheless, using this measure of seat quality has its drawbacks. Although the orderings appear to be carefully determined, we suspect they are not always perfect. More importantly, Ticketmaster's ordinal ranking of tickets is not informative about absolute differences in quality between seats. In the analyses below we simply assume that quality differences are uniform-i.e. the difference in quality between seats $j$ and $j+s$ is the same regardless of $j$. Specifically, we use $1-(j / J)$ as our index of quality, where $j$ is the seat's position in the "best available" order, and $J$ is the total number of tickets available. The best seat $(j=0)$ therefore has quality 1 , and the worst seat has quality $1 / J$.

\subsection{Secondary market data}

To obtain information about resales, we captured and parsed completed listings on eBay for all tickets to major concerts in the summer of 2004. From these pages we determined how many tickets were sold, on what date, at what price (including shipping), and the location of the seats. We only use auctions that ended with a sale (either via a bid that exceeded the seller's reserve, or via "Buy-it-now"). The auction pages also list information about the seller, including the seller's eBay username. We use this to distinguish between brokers and non-brokers: we categorize an eBay seller as a broker if we observe her selling 10 or more tickets in the data.

We also obtained data from StubHub, a leading online marketplace designed specifically for ticket resale. For every concert in our sample, we observe all tickets sold through StubHub, and for each transaction we observe the number of tickets sold, the seat location, the price (including shipping and fees), the date, and the seller identity and classification (broker versus non-broker).

Matching eBay auctions to specific concert events was straightforward, but assigning resales to specific seats was complicated because exact seat numbers were rarely reported in the eBay or StubHub auctions. We were able to determine the section and row for $75 \%$ of the resale transactions. For another $23 \%$ we could only determine the section. Beginning with transactions for which we observed both the section and row, we assigned resales to specific seats by spreading them evenly throughout the relevant section and row. For the remaining $2 \%$, our parser did not even detect the section, and we simply dropped these transactions from the analysis 16 We are left with 51,318 resold tickets (the vast majority of them on eBay).

15. A "comped" or complementary seat is one that was given away. Comps are typically around $1 \%$ of ticket sales (and are always less than 3\%) for the events in our sample. An open seat is an available seat that went unsold.

16. Dropping these sales means that our data will slightly understate the total amount of resale on eBay and StubHub for these events. 
The prior literature on resale has noted that adverse selection can be important in secondary markets 17 We tested for the possibility of adverse selection by examining auctions in which the seat's row was not clearly identified. If sellers withhold that information strategically, then auctions with unreported rows could be auctions with undesirable rows. However, we found that prices in auctions that specified the section only (no row) were not statistically different from prices in auctions that specified both section and row, suggesting this kind of adverse selection is not important-either because the sellers' private information is not especially important, or because the information is in fact communicated to the buyers in ways that our parser did not pick up.

For the empirical model we estimate later in the text, it would be ideal to observe all resale activity for the sample concerts. We do not know exactly how much of total resale activity is accounted for by eBay and StubHub. As explained in Section 2 in 2004 eBay was the largest single outlet for ticket resales, with StubHub the second largest. Where necessary in our analysis below, we assume that the combined market share of eBay and StubHub was 50\%. Based on the available survey evidence and conversations with executives in the industry, we believe this assumption is approximately correct. Of course, even if we knew eBay's and StubHub's exact market shares, we would have no way to verify if resales on these two sites were representative of resale activity more broadly. Given that both brokers and non-brokers have a significant presence on eBay, and we observe resales for the full range of ticket qualities, we expect our data are at least roughly representative of resale activity more broadly.

\subsection{Summary statistics}

The dataset covers 1.03 million tickets sold in the primary market for 56 concerts by 12 different artists. Table 1 provides detailed summary statistics for primary market sales. Of particular note is that the maximum number of price levels for a single event in our data is four, with most events offering tickets at only two different price levels. Table 2 provides additional summary statistics for resale transactions 18 Resellers make significant profits: the average markup is $41 \%$ over the face value, and $25 \%$ of resold tickets obtain markups above $67 \%$. On the downside for resellers, $26 \%$ of tickets are sold below face value. Resold tickets are not a random sample of those purchased in the primary market, and in particular the resold tickets tend to be of higher quality than non-resold tickets. The average seat quality of tickets purchased in the primary market is 0.50 , while the average seat quality of resold tickets is 0.61 (median is 0.65 ) 19

Seat quality is a key determinant of prices in both the primary and secondary markets, but there are a couple of important differences between these markets in the relationship of price to seat quality. In the primary market prices are based on coarse partitions of each venue, while resale prices reflect small differences in seat quality - every seat may have a different price. Also, primary market prices are weakly monotonically increasing in seat quality for a given event. In contrast, the examples in Figure 1 illustrate that resale prices are a rather noisy function of seat quality, and there are numerous instances of a low-quality seat resold at a higher price than a higher quality seat (for a given event). This is basic evidence of inefficiency in the resale market. On the one hand, the resale market allows price to be a more flexible function of seat quality.

17. As shown by Akerlof (1970) and Hendel and Lizzeri (1999), this is especially relevant for used durable goods, where imperfect information in the resale market can affect behaviour and outcomes in both the primary and resale markets.

18. In Table 1 an observation is an event, while in Table 2 an observation is a resold ticket.

19. An unreported semiparametric regression (using an adaptation of Yatchew's (1997) difference-based estimator for partial linear regression models) also shows that the probability of resale is increasing in seat quality. 
TABLE 1

Summary statistics: events $(N=56)$

\begin{tabular}{|c|c|c|c|c|c|c|c|}
\hline & \multirow[b]{2}{*}{ Mean } & \multirow[b]{2}{*}{ Std. Dev. } & \multirow[b]{2}{*}{ Min } & \multicolumn{3}{|c|}{ Percentiles } & \multirow[b]{2}{*}{$\operatorname{Max}$} \\
\hline & & & & 0.25 & 0.50 & 0.75 & \\
\hline \multicolumn{8}{|l|}{ Primary market } \\
\hline Tickets sold & 18286.20 & 6831.47 & 3169.00 & 13859.00 & 16920.00 & 21763.00 & 34844.00 \\
\hline Tickets comped & 184.39 & 147.12 & 0.00 & 60.00 & 145.00 & 316.00 & 494.00 \\
\hline Revenue (000) & 1481.14 & 508.16 & 266.33 & 1119.63 & 1377.48 & 1912.43 & 2323.90 \\
\hline Venue capacity & 18544.54 & 6824.16 & 3171.00 & 14085.00 & 17483.00 & 22087.00 & 35062.00 \\
\hline Capacity util. & 0.99 & 0.02 & 0.83 & 1.00 & 1.00 & 1.00 & 1.00 \\
\hline Average price & 90.54 & 44.35 & 43.38 & 54.48 & 68.21 & 144.15 & 187.24 \\
\hline Maximum price & 150.13 & 112.05 & 47.50 & 66.65 & 85.85 & 307.40 & 315.50 \\
\hline \# price levels & 2.71 & 1.07 & 1.00 & 2.00 & 2.00 & 4.00 & 4.00 \\
\hline$\%$ first week & 0.70 & 0.14 & 0.28 & 0.62 & 0.73 & 0.80 & 0.96 \\
\hline \multicolumn{8}{|l|}{ Secondary market } \\
\hline Tickets resold & 916.39 & 543.49 & 377.00 & 580.00 & 704.00 & 1101.00 & 3130.00 \\
\hline Resale revenue & 103.76 & 54.18 & 42.33 & 65.40 & 87.48 & 121.53 & 295.32 \\
\hline Percent resold & 0.05 & 0.03 & 0.03 & 0.03 & 0.04 & 0.06 & 0.17 \\
\hline Percent revenue & 0.08 & 0.06 & 0.03 & 0.05 & 0.06 & 0.09 & 0.37 \\
\hline
\end{tabular}

Notes: Revenue numbers are in thousands of US dollars. "\# price levels" is the number of distinct price points for the event. "\% first week" is the percentage of primary market sales that occurred within one week of the public onsale date. "Percent resold" is the number of resales observed in our data divided by the number of primary market sales, and "Percent revenue" is the resale revenue divided by primary market revenue.

TABLE 2

Summary statistics: resold tickets $(N=51,318)$

\begin{tabular}{lrrrrrrr}
\hline & & & & \multicolumn{4}{c}{ Percentiles } \\
\cline { 5 - 8 } & Mean & Std. Dev. & Min & 0.25 & 0.50 & 0.75 & Max \\
\hline Resale price & 113.23 & 80.91 & 3.50 & 66.25 & 91.50 & 135.00 & 2000.00 \\
Markup & 22.80 & 68.64 & -308.65 & -0.85 & 20.60 & 44.50 & 1686.40 \\
\% Markup & 0.41 & 0.75 & -0.98 & -0.01 & 0.32 & 0.67 & 14.86 \\
Seat quality & 0.61 & 0.27 & 0.00 & 0.37 & 0.65 & 0.85 & 1.00 \\
Days to event & 43.45 & 42.76 & 0.00 & 7.00 & 26.00 & 76.00 & 208.00 \\
Sold by broker & 0.54 & 0.50 & 0.00 & 0.00 & 1.00 & 1.00 & 1.00 \\
Sold below face value: & & & & & & 0.00 & 0.00 \\
$\quad$ by broker & 0.21 & 0.41 & 0.00 & 0.00 & 0.00 & 1.00 \\
$\quad$ by non-broker & 0.31 & 0.46 & 0.00 & 0.00 & 0.00 & 1.00 & 1.00 \\
\hline
\end{tabular}

Notes: Resale prices include shipping fees. Markups are calculated relative to the ticket's face value, including shipping and facility fees. Seat quality is based on the "best available" ordering in which Ticketmaster sold the tickets, as explained in the text, and is normalized to be on a [0,1] scale (1 being the best seat in the house). Brokers are eBay sellers who sold 10 or more tickets in our sample, or StubHub sellers who were explicitly classified as brokers.

On the other hand, some form of friction in the resale market causes significant variance in price conditional on seat quality 20 Our empirical model explains this fact as being a consequence of limited buyer participation in resale market auctions.

Our analysis emphasizes the consequences of limited price flexibility in the primary market on resale activity. In Figure 2 we present basic evidence in support of this view. By definition,

20. Since the resales represented in Figure 1 occurred at different times, the price variation could reflect changes in the market price over time. Sweeting (2012) finds that secondary market prices for Major League Baseball tickets decline significantly over time as the game date approaches. However, in our dataset we find that prices (conditional on seat quality) change relatively little: they decline slightly as the event date approaches, with a modest uptick in the last week before the event. 


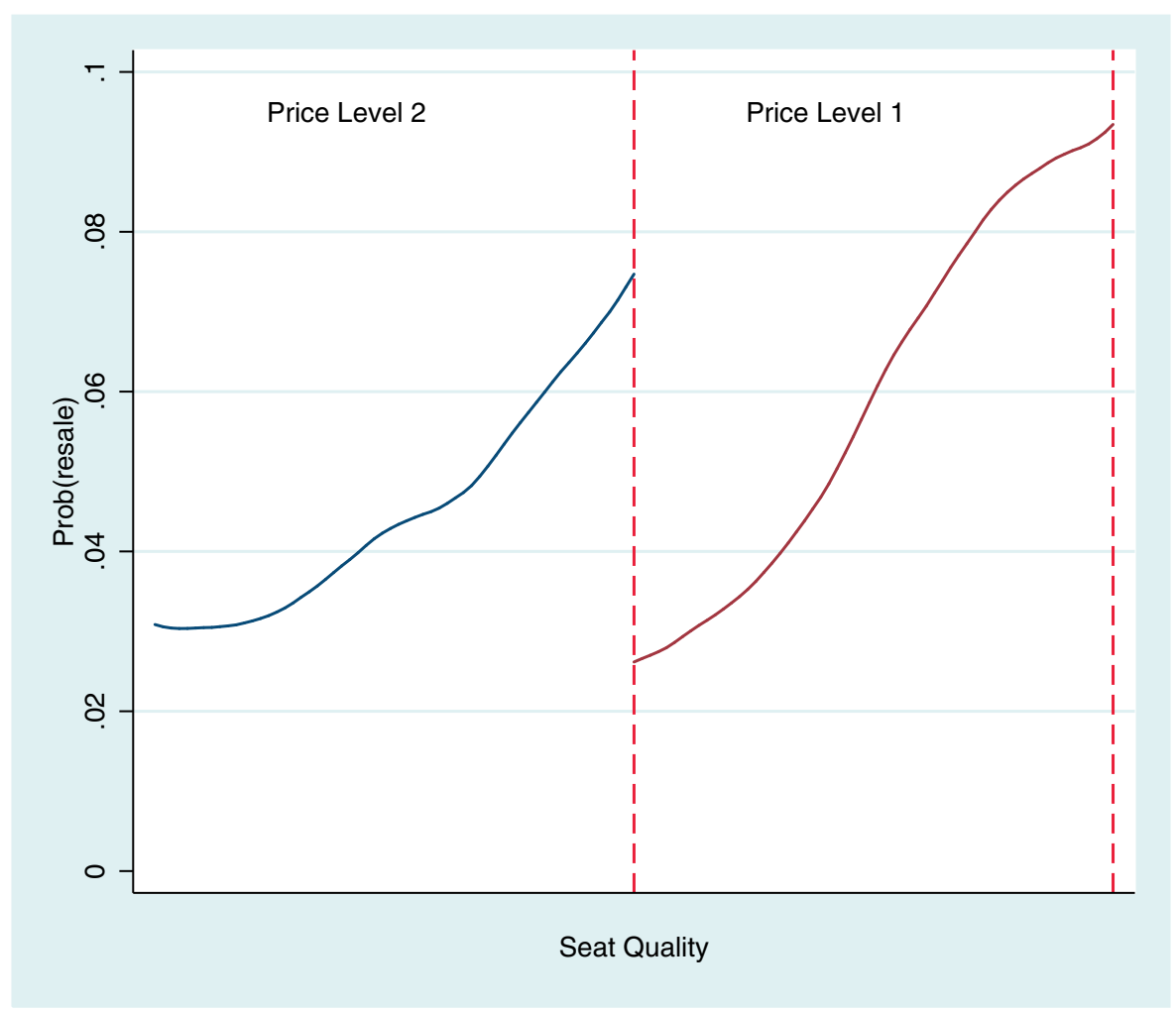

FIGURE 2

Probability of resale by price level. In generating this figure, only events with two or more price levels were used.

Relative seat qualities are calculated within price level for this figure, and the probability of resale is estimated using kernel-weighted local polynomial regression. So, for example, the probability of resale is on average higher for the best seats in price level 2 than for the worst seats in price level 1.

all seats in a given price level at a given event have the same face value. However, there can be thousands of seats in a given price level, and the difference in seat quality between the best and worst seats in the price level can be dramatic. At equal prices there will be higher demand for the good seats in a given price level than the bad seats. We therefore expect more resale activity for the relatively good seats in any given price level. Figure 2 shows exactly this pattern.

In the primary market, tickets typically go on sale 3 months before the event date. In Table 1 we report that (averaged across events) $70 \%$ of ticket purchases in the primary market occur in the first week. In the top panel of Figure 3 we depict the complete time-pattern of sales in the primary market. It is clear that sales in the primary market are highly concentrated at the very beginning. The time-pattern of sales in the resale market is less concentrated than the primary market, as shown in the lower panel of the figure. In Table 2 we report that $50 \%$ of resale transactions occur within 26 days of the event, and $25 \%$ of resale transactions are within 7 days of the event. In the model presented in the next section we assume primary market transactions occur in period 1, and resale transactions occur in period 2. The above facts suggest this is a reasonable simplification.

The empirical model we estimate below allows consumers to invest in early arrival-i.e. to compete to be first in line to buy tickets in the primary market. Consumers' incentives to do so 

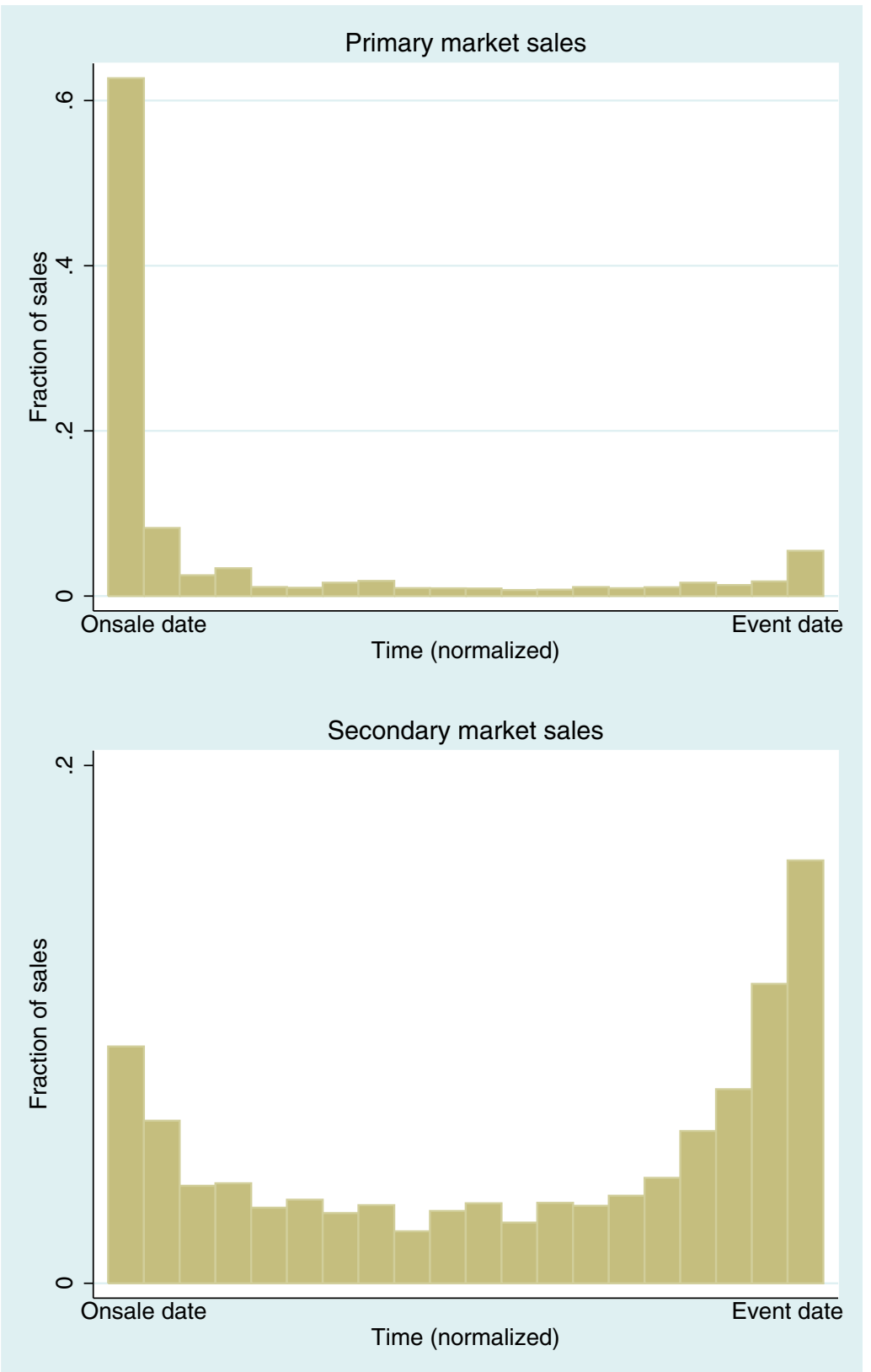

FIGURE 3

Timing of sales in primary and secondary markets. Time is normalized to make it comparable across events; it is measured as (days since onsale)/(total days between onsale and event). The histogram in the top panel represents the 1,034,353 tickets sold by Ticketmaster; the bottom panel represents the 51,318 tickets resold on eBay or StubHub.

depend on the degree to which the tickets are underpriced. In fact there is substantial variation across events in how compressed the sales are in time. For about $10 \%$ of concerts, more than $75 \%$ of the seats are sold in the very first day. But the median concert sells only $25 \%$ of capacity in the first day, and less than $75 \%$ in the first week. This suggests that people make costly efforts 
to show up early when excess demand is expected to be high: if it were costless to show up early, we would not expect to see any concerts with sales so spread out over time. Indeed, the concerts in our sample with the largest resale markups also tend to sell a higher fraction of tickets in the first day.

The total profit (i.e. aggregate markup) obtained from ticket resale in our data is slightly over $\$ 1.17$ million. This is equivalent to $1.4 \%$ of the total primary market revenue for these events. As a measure of "money left on the table" this suggests a fairly modest amount of forgone profit by firms in the primary market, even if we are accounting for only half of resale activity. This may be misleading, however, because modified pricing policies that capture some of this value may also be more efficient at extracting consumer surplus. We address this issue in the counterfactual analyses in Section 6

Lastly, we wondered if resale prices depend on the number of tickets grouped together. In particular, do pairs of tickets tend to sell for a higher price (per ticket) than single tickets? This would affect modelling assumptions in the next section. In an unreported regression, we regress $\log$ (ResalePrice) on event dummies interacted with seat-quality deciles (i.e. flexible event and seat quality controls), and dummy variables for each of $1, \ldots, 5$ tickets resold together. We found that the number of tickets has no significant effect on the resale price.

\section{MODEL}

An important driver of resale is arbitrage: profit-seeking behaviour that takes advantage of underpricing (of particular seats, at least) in the primary market. Underpricing implies excess demand, requiring a mechanism for rationing tickets to buyers. We adopt a standard approach in which buyers make purchase decisions in a sequence, with choice sets that are updated to reflect purchases made by buyers who came previously in the sequence 21 The ordering of buyers is far from innocuous in this analysis, however. If we assumed that buyers were ordered from highest willingness to pay to lowest, this would yield an efficient allocation of tickets in the primary market, eliminating the principal motive for resale. Assuming that buyers are randomly ordered is more plausible, but precludes the possibility that high-value consumers may tend to arrive early in the sequence (because the benefits of being early are higher for these buyers than for low-value buyers), or that high-value consumers may tend to be late in the arrival sequence (because high-value buyers tend to have a high opportunity cost of time).

For these reasons it is essential to let the data reveal the arrival sequence. But simply estimating the correlation between willingness to pay and arrival order in the primary market would not reveal how that correlation would be different if resale were banned or if resale were frictionless. In other words, just as the initial allocation of tickets in the resale market is endogenous, the arrival order of buyers in the primary market is also endogenous. How much effort people exert to buy tickets in the primary market depends on the existence and characteristics of the subsequent resale market. Since the potential profits from resale are in fact large (as documented above in Section 3.3, rent-seeking costs may also be large.

We therefore propose a model of resale with three sequential stages of decision making. In the first stage buyers (consumers and brokers) make strategic effort choices in an arrival game that determines the ordering of buyers in the primary market. In the second stage buyers make purchase decisions in the primary market. In the third stage the resale market takes place. The equilibrium of the model is one in which all buyers behave optimally given their expectations

21. Leslie (2004) implements a similar approach. See Mortimer and Conlon (2007) for an alternative approach to demand estimation with stock-outs. 
about payoffs in subsequent stages, and their expectations are on average correct given that all agents in the model are behaving optimally.

The inclusion of a strategic arrival game is the most important way in which our modelling approach differs from the prior research. Another departure is that in our model we do not allow the producer to sell tickets in multiple periods. This is a simplifying assumption, motivated by the fact that there is minimal overlap in the timing of primary market activity and resale activity, and also by the fact that no producer in our dataset implements any form of dynamic pricing 22 Second, we allow consumers (in addition to brokers) to resell tickets. This is important because it fundamentally affects how consumers value tickets in the primary market, and also because it allows consumers to capture some of the rents from reselling that only accrue to brokers in the prior research. It also reflects reality: as noted above, $46 \%$ of the resold tickets in our dataset appear to have been sold by non-brokers.

In the following sections we outline the structure of the model. To keep the exposition as simple as possible, we defer some of the details (such as functional form assumptions and simplifications made to reduce computational burden) until Section 6.

\subsection{Primitives}

There are $M$ potential buyers in the market, a fraction $\beta$ of which are brokers, and a fraction $1-\beta$ who are consumers. The distinction between the two types is that brokers get no utility from consuming a ticket: if they purchase in the primary market, it is only with the intention of reselling at a profit. Consumers are heterogenous in their willingness to pay $(\omega)$ for seat quality, and in their $\operatorname{cost}(\theta)$ of arriving early in the primary market. These two dimensions of heterogeneity are jointly distributed with marginal density function $f_{c}(\omega, \theta)$. Brokers' costs of arriving early in the primary market are distributed with marginal density $f_{b}(\theta)$.

If a consumer attends the event, she obtains gross utility $U(v ; \omega)$, where $v$ is the seat quality. Buyers' efforts to arrive early in the primary market (in order to secure higher quality tickets) are costly: we use $C(t ; \theta)$ to denote the cost of arriving at time $t$ for a buyer of type $\theta$. Letting $p$ denote the ticket price in the primary market, a consumer who purchases a ticket in the primary market at time $t$ and attends the event gets net utility equal to

$$
U(\nu ; \omega)-p-C(t ; \theta) .
$$

For a buyer who purchases in the primary market and then resells at price $r$ in the secondary market, the net payoff is

$$
r-p-C(t ; \theta)-\tau,
$$

where $\tau$ is the transaction cost of reselling the ticket. The consumer who buys the resold ticket earns net utility

$$
U(v ; \omega)-r-C(t ; \theta) .
$$

In this case $C(t ; \theta)$ may be zero, since the consumer may have chosen not to make any effort to buy a ticket in the primary market.

In essence, the objective of our empirical exercise is to use data on prices ( $p$ and $r$ ), quantities, and the timing of primary market sales $(t)$ to estimate the distributions of buyer heterogeneity $\left(f_{c}\right.$ and $f_{b}$ ) and the parameters of the utility and arrival cost functions $(U$ and $C$ ). Having recovered

22. Note, however, that our model includes uncertainty of the same kind emphasized in Courty (2003). Namely, consumers do not know whether they will be able to attend the event in period one (due to the possibility of a schedule conflict). 
these primitives, we can then simulate market outcomes under various changes to the market environment (e.g. reductions in the transaction cost, $\tau$, or increases in the sophistication of primary market pricing).

\subsection{Arrival game}

Buyers' arrival times in the primary market are solutions to an optimization problem that weighs the benefits and costs of early arrival. A buyer's type is defined as the triple $(b, \omega, \theta)$, with $b=1$ for brokers. In the arrival game buyers have private information about their own types and have common knowledge of the distributions of types and the number of players. Strategies in the arrival game are defined as mappings from types to arrival times: $t \in \mathfrak{R}^{+}$. A buyer can choose to arrive early in the primary market (i.e. choose a low value of $t$ ) in order to secure a high-quality seat, but she incurs arrival costs represented by the function $C(t ; \theta)$. Arrival costs are increasing in $\theta$, and decreasing in $t$ at a rate that increases with $\theta$ (i.e. $\left.\partial^{2} C / \partial t \partial \theta<0\right)$.

The arrival cost function is intended to represent buyers' time costs or queuing costs: due to congestion, participating early in the primary market typically requires repeated attempts to connect to Ticketmaster by phone or internet. Attention costs are also potentially important, as it may require effort for buyers to become informed of the exact date and time the tickets go on sale, or it may be costly to break free from work to call in at that time. Alternatively, the cost type $\theta$ could be interpreted as buyers' ability to plan ahead: some buyers may find it costlier than others to commit to an event three months in advance. Regardless of interpretation, the important assumption here is that buyers are heterogeneous in both benefits and costs of early arrival (through $\omega$ and $\theta$, respectively). If there were no heterogeneity on the cost side, buyers would arrive sorted by willingness to pay $(\omega)$, and our model would predict that the primary market allocation is fully efficient.

Individually, a buyer's incentive to choose an early arrival time (low $t$ ) is that earlier arrivals get to purchase higher quality tickets. But the ordering of agents in the primary market depends on the arrival times chosen by all agents: only relative arrival times matter. Since types are private information, upon choosing $t$ an agent is still uncertain about her place in the eventual sequence. In other words, letting $z$ denote the position in the buyer sequence, from the perspective of an individual buyer the mapping from $t$ to $z$ is stochastic. Moreover, the payoff associated with position $z$ is also uncertain, because it depends on choices made by buyers earlier in the sequence, and it depends on uncertain outcomes in the resale market (which we describe in more detail below). We denote the expected payoff associated with arrival position $z$ as $V_{0}(z ; b, \omega)$. The dependence on $b$ and $\omega$ reflects the fact that expected payoffs differ for brokers versus consumers, and that (for consumers) payoffs depend on the marginal value of seat quality. Naturally, $V_{0}$ is decreasing in $z$ for all buyers: early positions are the most valuable.

Agents in the arrival game therefore solve the following maximization problem:

$$
\max _{t} \quad \sum_{z} V_{0}(z, b, \omega) g(z \mid t)-C(t ; \theta)
$$

where

$$
g(z \mid t)=H(t)^{z-1}(1-H(t))^{M-z}\left(\begin{array}{c}
M-1 \\
z-1
\end{array}\right) \text { for } z=1, \ldots, M
$$

In this notation $g(z \mid t)$ is the probability of being in position $z$ given arrival time $t$, and the function $H(t)$ is the equilibrium distribution of chosen arrival times across all agents. Because the number 
of buyers in our empirical application is very large, for purposes of estimation we treat the mapping from $t$ to $z$ as deterministic, with $z=H(t) \cdot M$

Importantly, note that the inclusion of an arrival game makes the welfare impact of resale ambiguous. Resale increases total surplus by reallocating tickets to consumers with the highest valuations, but it may also increase buyers' costly efforts in the arrival game-and these costs may more than offset the gains from reallocation. To understand why, consider a very simple example in which a single ticket is sought by three potential consumers with net valuations of 30,20 , and 10. By incurring a cost of 6, each buyer can arrive early. If a buyer is the only one to arrive early, she gets the ticket with probability one; if two or more buyers arrive early (or if no one incurs the cost), each has an equal chance of getting the ticket. In the absence of resale, only the two consumers with the highest valuations will arrive early, and expected surplus is $\frac{1}{2}(30+20)-2(6)=13$. If the ticket can be costlessly resold, then its value becomes 30 for all three consumers, and all three have an incentive to incur the arrival cost. Expected surplus is $30-3(6)=12$ : the additional costs incurred in the arrival game (6) more than offset the gains from reallocation (5). The key idea is that the possibility of resale increases lowvaluation consumers' (or brokers') incentives to obtain the tickets, increasing costly effort in the arrival game.

\subsection{Primary market}

In the primary market stage, buyers make purchase decisions in the order that was determined in the arrival game. Buyers are limited to choosing from the set of unsold tickets at their turn in the sequence, and each buyer is limited to buying one ticket. When making their purchase decisions, buyers are forward looking. Consumers know that they will either consume the ticket (i.e. attend the event) or resell the ticket. Brokers who purchase in the primary market will always try to resell the ticket. We assume that both brokers and consumers incur transaction costs if they choose to resell, denoted $\tau_{b}$ and $\tau_{c}$, respectively. The buyers in the secondary market are the consumers who chose not to purchase (or were rationed) in the primary market.

Buyers' decisions in the primary market are driven by their expectations about the resale market. Our model incorporates four sources of uncertainty about resale market outcomes. The first is randomness in the arrival sequence, as mentioned above. The second is the possibility of unanticipated schedule conflicts 24 We assume there is a probability $\psi$ that a given consumer will have zero utility from attending the event, with the uncertainty being resolved between the primary and secondary market stages. A third source of uncertainty is randomness in auction participation. As explained below, we clear the secondary market using a sequence of auctions, with a random subset of potential buyers participating in each auction. Realized outcomes in the resale market depend on the particular subsets of buyers who bid for each ticket.

The fourth source of uncertainty is an aggregate (event-specific) shock to demand. We assume that the distribution of willingness to pay $\left(f_{c}\right)$ is subject to shocks that are unobservable at the primary market stage. Buyers know the distribution of these shocks, but only observe the realized value of the shock after the primary market stage is complete. Incorporating this fourth kind of uncertainty is necessary if we want the model to fit the data. For many events we observe both consumers and brokers reselling tickets below face value. For consumers, such transactions could be explained by unanticipated schedule conflicts; but for brokers, we would never observe resales below face value unless brokers sometimes overestimate the strength of demand. Essentially,

23. For large $M, g(z \mid t)$ converges to a point mass on $E(z \mid t)$, which is just $H(t) \cdot M$.

24. This source of uncertainty is equivalent to the uncertainty emphasized by Courty (2003) in his model of ticket resale. 


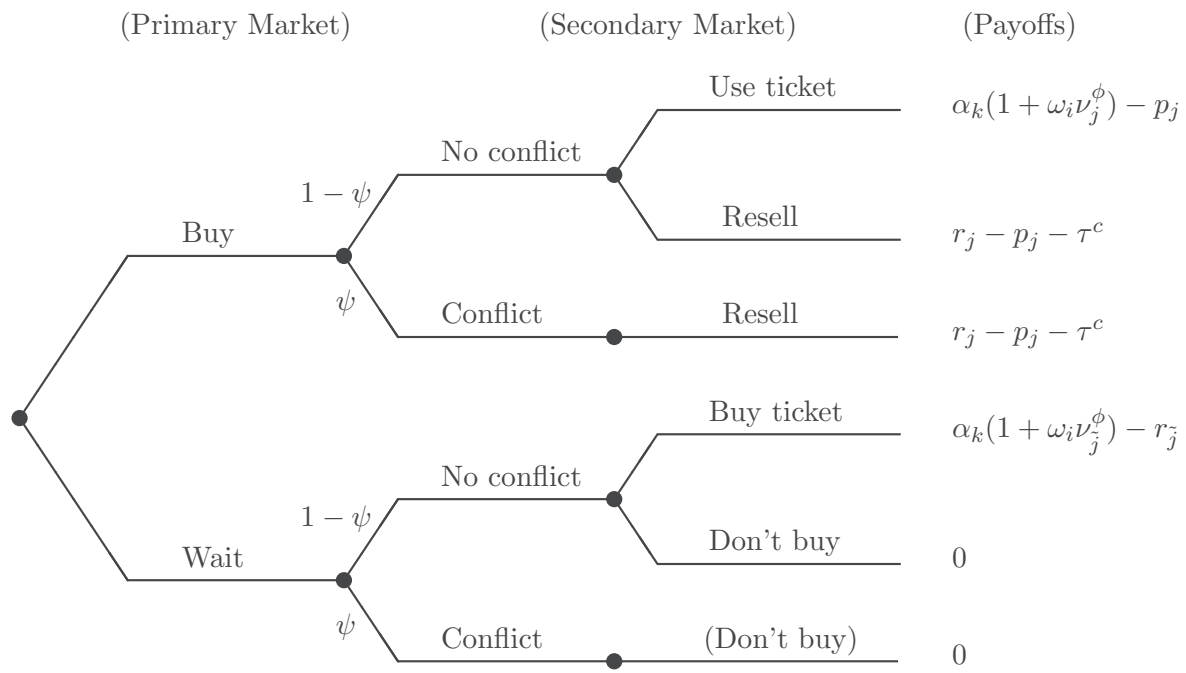

FIGURE 4

The consumer's decision problem

uncertainty about the strength of demand allows us to explain why some events sell out in the primary market but then have very thin resale markets with very low prices, while other events do not sell out in the primary market but then have very high prices in the resale market.

The price of a ticket in the resale market is principally a function of its quality, but it will also depend on the realizations of the uncertainties described above. Letting $R_{j}$ be the random variable representing the resale price of seat $j$, the decision problem for a broker in the primary market is to purchase the ticket $j$ that maximizes

$$
E\left(u_{j}^{b}\right)=E\left(R_{j}\right)-p_{j}-\tau_{b},
$$

where $p_{j}$ is the primary market price of ticket $j$, and the expectation is with respect to the four sources of uncertainty described above. Of course, if the transaction cost $\tau_{b}$ exceeds the expected resale profits, a broker also has the option of not purchasing a ticket (and receiving a payoff of zero) 25

A consumer's decision problem is somewhat more complicated, as illustrated in Figure 4 If a consumer buys ticket $j$ in the primary market, with probability $\psi$ she will have a schedule conflict and be forced to resell the ticket, obtaining some price $R_{j}$. While not illustrated explicitly in the figure, she also has the option of discarding the ticket if the transaction cost is higher than the resale profit, in which case her payoff is $-p_{j}$. If she has no schedule conflict, she will have the choice of reselling or using the ticket, with the latter option delivering a net utility of $U_{j}(\omega)-p_{j}$. The expected payoff from buying ticket $j$ is therefore

$$
\begin{aligned}
E\left(u^{c} \mid \operatorname{buy} j\right)= & -p_{j}+\psi E\left(\max \left\{0, R_{j}-\tau_{c}\right\}\right) \\
& +(1-\psi) E\left(\max \left\{0, R_{j}-\tau_{c}, U\left(v_{j}, \omega\right)\right\}\right) .
\end{aligned}
$$

25. We omit costs incurred in the arrival game from the present discussion, because those costs are already sunk when the primary market decision is made. 
If instead the consumer chooses not to buy a ticket in the primary market, but rather wait until the secondary market, her expected utility is given by

$$
\left.E\left(u^{c} \mid \text { wait }\right)=(1-\psi) E\left(\max \left\{0, U\left(v_{\tilde{j}}, \omega\right)-R_{\tilde{j}}\right)\right\}\right) .
$$

In this case, the consumer is not only uncertain about what the prices will be in the resale market, she is also uncertain about which ticket (if any) she will be able to buy. We use the loose notation $\tilde{j}$ to indicate that ticket quality is itself a random variable for a consumer who chooses to delay her purchase.

\subsection{Resale market}

The result of the primary market stage is an allocation of tickets to buyers. Some brokers and consumers hold tickets, and some consumers remain without tickets (either because they elected to wait for the secondary market, or because the event sold out before their turn in the buyer sequence). This allocation is not necessarily efficient, since the consumers without tickets may have higher willingness to pay than some ticketholders. In the resale market stage, ticketholders have the opportunity to resell their tickets to higher-value consumers.

A natural way to clear the resale market would be to calculate every buyer's willingness to pay for every ticket (with the ticketholder's willingness to pay being equal to her reservation price), and then find a vector of prices such that there is no excess demand for any ticket. Although this approach is feasible in our model, it has one major drawback: it predicts resale prices that are monotonic in seat quality, which is very far from what we observe in the data. While resale prices increase on average as a function of seat quality, there is considerable variance in observed prices conditional on seat quality.

To accommodate this feature of the data, we clear the resale market using a sequence of privatevalues, second-price auctions with limited bidder participation 26 We begin with the highest quality ticket and randomly select $L$ bidders 27 The owner of the ticket is offered a price equal to the second-highest willingness to pay among those $L$ bidders. If the offer exceeds the owner's reservation price, then the ticket is transacted at that price: the bidder with the highest willingness to pay gets the ticket, and both seller and buyer exit the market 28 If the offer is below the reservation price, the ticket remains with the seller. In this case, if the seller is a consumer, she uses the ticket herself and gets the consumption utility defined above; and if the seller is a broker, she gets utility zero. Losing bidders remain in the pool of potential buyers and may be selected to participate in another auction. This process is then repeated for all tickets that were purchased in the primary market, in order of decreasing quality 29 In this mechanism every ticket purchased in the primary market is for sale in the resale market, regardless of whether it is owned by a broker or consumer 30

26. This assumption also matches the actual functioning of auctions on eBay.

27. In the estimation we treat $L$ as a random variable and estimate its mean.

28. We allow only one transaction per period for any individual. So we do not allow consumers to buy in the primary market, sell in the resale market, and then buy another ticket in the resale market. We also rule out reselling any ticket twice.

29. This ordering implies an efficient allocation (among all potential bidders) if transactions costs were zero and all bidders participated in all auctions.

30. Note that even in the limit as $L$ grows large, our approach differs from the "market-clearing price vector" approaches proposed for clearing assignment markets (e.g. Shapley and Shubik, 1972 and Crawford and Knower, 1981). Instead of assuming that all buyers and all sellers are in the market at the same time and are aware of all other traders, 
Our model assumes that both buyers and sellers are myopic within the resale market stage (in contrast to their forward looking behaviour in the arrival game and primary market). Potential buyers do not take into account the possibility of participating in another auction when determining their bids, and sellers' reservation prices assume a one-time opportunity to sell. The assumption is perhaps strongest in the context of brokers, who may be more likely to reject current low bids and hold a new auction. This does not affect our estimate of the value captured by brokers, however, since we observe their actual profitability. Also, the majority of ticket auctions on eBay and StubHub end with a sale, so in practice sellers rarely end up re-listing their tickets. We do not have data indicating whether buyers re-enter the secondary market if after losing an auction. To the extent they do, the resale market would be more efficient than our model estimates it to be, and our results would underestimate the allocative efficiency gains from resale.

\section{ESTIMATION AND RESULTS}

Given the structure of payoffs described above, a rational expectations equilibrium is one in which: (i) brokers and consumers make decisions optimally in the arrival and primary market stages, given their expectations about payoffs in the resale market; and (ii) those expectations are on average correct given optimal decision-making in the arrival game and primary market 31 The challenge is finding expectations that rationalize a set of arrival times and primary market decisions that in turn lead to resale market outcomes consistent (on average) with those expectations.

In principle, we could employ an estimation algorithm that finds an equilibrium (i.e. a fixed point in the mapping of expectations into average resale market outcomes) at every iteration of the parameter search 32 However, to simplify and streamline the computation, we estimate the model in two steps 33 In the first step, we use the data to estimate probability distributions for the various resale market outcomes that are relevant to buyers' primary market decisions. We then estimate the full model in a second step, with the first-step estimates standing in for buyers' beliefs. This approach effectively assumes that when buyers made their decisions in the primary market, their expectations about the resale market were consistent with the outcomes we actually observe in the data.

Although the two-step approach is conceptually simple, estimating the model is still computationally intensive. We make several simplifying assumptions to ease the computational burden. In this section we outline these assumptions and specify the functional forms used for the utility function $(U)$ and the arrival cost function $(C)$. We then discuss identification and present the results.

\subsection{First step}

Agents in our model must have beliefs about three key probability distributions: (i) the distribution of other buyers' arrival times in the primary market, $H(t)$; (ii) the distribution of a ticket's resale price, $R_{j}$, conditional on its quality; and (iii) the distribution of final payoffs for a consumer who

we assume that buyers arrive randomly and sequentially, and do not anticipate participating in later auctions if they lose the current auction. Hence, while buyers in our model are forward-looking in the primary market stage, within the resale stage they behave myopically.

31. Forward-looking consumer behaviour with rational expectations of future market outcomes is also essential in recent papers by Gowrisankaran and Rysman (2011), and Hartmann and Nair (2010). See also Chevalier and Goolsbee (2009).

32. A previous version of this article describes such an approach.

33. We are grateful to an anonymous referee for suggesting this simplification. 
chooses to bypass the primary market in hopes of obtaining a ticket in the secondary market. We estimate each of these distributions from the data in a first step, and then take those estimates to represent agents' beliefs in the second-step estimation of the model's deep parameters.

5.1.1. Distribution of arrival times. We use the primary market sales data to estimate the distribution of arrivals, $H(t)$. (We assume that the number of sales we observe on day 1 is the number of day-1 arrivals, and so on.) Separately for each event $k$, we use maximum likelihood to fit the two parameters of the Weibull distribution to the observed data on daily sales 34 The resulting parametric estimate, $\hat{H}_{k}(t)$, is then used to represent buyers' beliefs about the distribution of arrival times in the second step of the estimation. The reason for computing event-specific distributions is that buyers likely have event-specific beliefs about how hard it will be to get tickets in the primary market: for a hot concert that is well known to be underpriced, everyone knows that there will be a rush to buy the tickets when they go on sale.

5.1.2. Distribution of resale prices. We assume that buyers believe resale prices are lognormally distributed, conditional on quality. If $R_{j k}$ denotes the resale price of seat $j$ at event $k$, then

$$
\log \left(R_{j k}\right) \sim N\left(\bar{r}_{j k}, \sigma_{r k}\right),
$$

where the expected resale price is a quadratic function of quality $(v)$ :

$$
\bar{r}_{j k}=\gamma_{0 k}+\gamma_{1} v_{j}+\gamma_{2} v_{j}^{2} .
$$

We obtain estimates of $\gamma$ by regressing log resale prices on quality and quality squared (and event fixed effects) using all of the resold tickets in our sample. When computing buyers' beliefs about resale prices in the second step of our estimation procedure, we then simply replace $\bar{r}_{j k}$ with the predicted value from this regression, and also replace $\sigma_{r k}$ with its estimated value from the regression.

5.1.3. Distribution of payoffs for consumers who bypass primary market. Estimating the expected final payoff for a consumer who bypasses the primary market is more complicated, since payoffs are not observable in the data. We construct an approximation by (i) calculating for every ticket the payoff the consumer would get if she purchased that ticket in the secondary market at its expected resale price, and then (ii) computing a probability-weighted sum of these payoffs, where the probability weight for each ticket is an estimate of the probability that the consumer will end up purchasing that ticket. Specifically, we calculate

$$
\hat{u}_{i}^{c} \mid \text { wait }=\sum_{j=1}^{J} \frac{1}{\tilde{N}} \hat{s}_{j}\left[U\left(v_{j}, \omega_{i}\right)-\bar{r}_{j}\right],
$$

where $U\left(v_{j}, \omega_{i}\right)-\bar{r}_{j}$ is the utility consumer $i$ would get if she purchased seat $j$ at its expected resale price $\bar{r}_{j}$ (calculated as described earlier), and $\hat{s}_{j} / \tilde{N}$ is an estimate of the probability she would get seat $j$. The number of potential buyers, $\tilde{N}$, is the number of non-brokers who did not have a schedule conflict: $\tilde{N}=(1-\beta)(1-\psi) N . \hat{s}_{j}$ is an estimate of the probability that seat $j$ will 
be resold, obtained from a simple linear probability model: for each ticket we create an indicator for whether that ticket was sold in the secondary market, and we regress the indicator variable on a cubic polynomial in seat quality. The predicted values from the regression are our predicted resale probabilities, $\hat{s}_{j}$.

This approximation assumes that all potential buyers are equally likely to get a given ticket, and it does not take into account the full distribution of resale prices that might be paid for any given seat. It simply calculates the conditional mean payoff. Both of these assumptions are problematic, since our model implies that some buyers will be more likely to get tickets than others, and that there is considerable variance in resale prices even conditional on seat quality. Nevertheless, we expect our approach to deliver a reasonably good estimate, and in any case the accuracy of the calculation turns out not to matter very much. We estimate that the expected payoff to waiting is generally near zero, since buyers who bypass the primary market are unlikely to get a ticket, and if they do they will tend to pay a high price and earn little surplus 35

\subsection{Second step}

We assume that the distributions of buyers' types $\left(f_{c}\right.$ and $\left.f_{b}\right)$ are lognormal. For consumers

$$
(\log \omega, \log \theta) \sim N\left(\left[\begin{array}{l}
\mu_{\omega} \\
\mu_{\theta}
\end{array}\right],\left[\begin{array}{cc}
\sigma_{\omega}^{2} & \sigma_{\omega \theta} \\
\sigma_{\omega \theta} & \sigma_{\theta}^{2}
\end{array}\right]\right),
$$

and for brokers $\omega=0$ with

$$
\log \theta \sim N\left(\delta_{b} \mu_{\theta}, \sigma_{\theta}^{2}\right) .
$$

Thus we estimate the means and variances of willingness to pay and arrival cost, and for consumers we estimate the correlation between willingness to pay and arrival cost. The distribution of arrival cost types for brokers is assumed to have the same variance as for consumers, but the mean is scaled by $\delta_{b}$. This allows for the possibility that brokers have better technologies for arriving early in the buyer sequence (as is often alleged in the news media), in which case we would expect our estimate of $\delta_{b}$ to be less than one.

Let $v_{j} \in(0,1]$ denote the quality of ticket $j$, measured as described in Section 3.136 We assume consumer $i$ 's gross utility from attending event $k$ in seat $j$ is

$$
U_{i j k}=\alpha_{k}\left(1+\left(\omega_{i}+\Delta_{k}\right) \nu_{j}^{\phi}\right)
$$

where $\omega_{i}$ is consumer $i$ 's willingness to pay for seat quality, and $\Delta_{k}$ is a mean-zero shock to the demand for event $k$. Event-specific demand shocks allow the model to explain why some sold-out events have low resale prices, while other events that did not sell out can have high resale prices. Since buyers do not know the realization of $\Delta_{k}$ when they make their primary market decisions, there is some risk in purchasing tickets with the sole intention of reselling them. For purposes of estimation, we assume that $\Delta_{k} \sim N\left(0, \sigma_{\Delta}^{2}\right)$.

The chosen functional form for utility implies an intuitive interpretation of $\omega$ : when $\Delta_{k}=0$, the ratio of a consumer's willingness to pay for the best seat $\left(v_{j}=1\right)$ versus the worst seat $\left(v_{j}=0\right)$

35. This argument does not help when we perform counterfactuals, since in that case the parameters change and the expected payoff to waiting may increase. But we take a different approach to computing expectations in the counterfactual analysis, which we explain below.

36. If $j$ is the ticket's position in the "best available" order, and there are a total of $J$ available, then $v_{j} \equiv 1-(j / J)$. 
is just $1+\omega$. The curvature term, $\phi$, captures the potential non-linearity of premia for high-quality seats (as evidenced in Figure 1).

The event-specific terms $\alpha_{k}$ are intended to capture differences in the relative strength of demand across events. Since estimating the $\alpha_{k}$ 's adds 56 parameters to an already difficult nonlinear optimization problem, we take a simple (but reasonable, we think) shortcut. We estimate event fixed effects in an auxiliary regression of resale prices on seat quality and seat quality squared. We then plug in the estimated fixed effects $\hat{\alpha}_{k}$ in the utility specification above.

As explained above, we clear the resale market with a sequence of auctions. We assume that the number of bidders in the auction for seat $j$ is $L_{j}=1+\tilde{L}_{j}$, with $\tilde{L}_{j} \sim \operatorname{Poisson}\left(\mu_{L}\right)$. We explain below how the data identify $\mu_{L}$.

The parametric form of the arrival cost function is

$$
C(t ; \theta)=c_{0}\left(\frac{\theta}{t}-1\right)^{2}, \text { for } t \in(0, \theta] .
$$

Thus, if a consumer chooses $t=\theta$, she incurs no costs in the arrival game. The $\theta$ 's can be interpreted as the "exogenous" arrival times: the times at which buyers would have arrived in the primary market in the absence of any strategic efforts to arrive early.

The optimization problem solved by buyers in the arrival game is a continuous problem, but it does not have a closed-form solution. Consequently, it speeds computation dramatically to discretize the set of possible arrival times. We have each buyer $i$ choose $t_{i}$ from a discrete grid on $\left(0, \theta_{i}\right]$. For the results reported below, this grid has 60 evenly spaced points.

As a final way to reduce the computational burden, instead of simulating outcomes for events with thousands of seats, we simulate events with 400 seats, and then scale up the predictions to match the size of the event in question. For example, for an event with 10,000 seats, with 4,000 and 6,000 seats in two respective price levels, we simulate primary and secondary market outcomes for an event with 400 seats, with 160 and 240 seats in the two respective price levels. We then "scale up" by applying the predictions for seat 1 in the simulated event to seats $1-25$ in the actual event, the predictions for seat 2 to seats $26-50$, and so on 37

Two important variables in our model are neither known to us as data nor identified by the data as parameters. The first is the size of the market, $M$. In the estimates reported below, we fix $M$ to be 2.5 times the capacity of the event. The second is the fraction of total resales that our data account for. As explained above, we use the available information and assume that eBay and StubHub account for 50 percent of total resales. This factors into the estimation when we match predicted resale probabilities to observed resale outcomes: we simply divide in half the probabilities predicted by the model (i.e. we match the data to the probability of resale times the probability of observing that resale).

The transaction cost for brokers, $\tau_{b}$, could in principle be identified by variation in the data. As a practical matter, however, we found identification of this parameter to be weak 38 We therefore fix this parameter at a value that reflects the literal transaction costs of selling a ticket on eBay. We set $\tau_{b}=\$ 3.43$, which is the average selling fee (listing fee plus final-value fee) paid by ticket-sellers on eBay. Estimates of the other parameters were not sensitive to small changes in the assumed value of $\tau_{b}$.

37. This introduces additional noise into our estimator, but in principle we can eliminate as much of this noise as we want by increasing the size of the simulated event up to the size of the actual event.

38. Small changes to $\tau_{b}$ affect a very small fraction of transactions among a small subset of simulated agents (since the fraction of buyers who are brokers is estimated to be small). So our simulated GMM routine has difficulty converging on an optimal value for this parameter. (If we had the computational power to dramatically increase the number of simulated buyers, we expect this problem would go away.) 
To summarize, there are 13 parameters to be estimated: the parameters of the buyer-type distributions $\left(\mu_{\omega}, \mu_{\theta}, \sigma_{\omega}, \sigma_{\theta}, \sigma_{\omega \theta}, \beta, \delta_{b}\right)$, the non-linearity parameter in the utility function $(\phi)$, consumers' transaction costs $\left(\tau_{c}\right)$, the probability of a schedule conflict $(\psi)$, the standard deviation of the event-specific demand shock $\left(\sigma_{\Delta}\right)$, the mean number of bidders in the resale auctions $\left(\mu_{L}\right)$, and the scaling parameter in the arrival cost function $\left(c_{0}\right)$.

Since the equilibrium of the model described above cannot be derived analytically, we estimate the model by simulated GMM. A wide range of moment conditions could potentially be incorporated in the estimation. For the results reported below, we use a set of moments chosen to reflect the key sources of identifying variation in the data: the fraction of available tickets sold in the primary market ( 1 moment); average fraction of tickets resold by consumers (1 moment); average fraction of tickets resold by brokers ( 1 moment); average resale price (1 moment); average quality of resold tickets, separately for broker resales and non-broker resales (2 moments); 5 th, 10th, 25th, 75th, 90th, and 95th percentiles of the resale price distribution (6 moments) and 25 th and of the resale seat quality distribution ( 6 moments); the fraction of primary market sales occurring in each of five time "buckets" (5 moments) 39 the fraction of first-day sales that are in the top price level ( 1 moment); the fraction of first-day sales that are in the second price level (1 moment); the fraction of sales in days 2-7 that are in the top price level (1 moment); the fraction of sales in days 2-7 that are in the second price level (1 moment); and the standard deviation of the residuals from a regression of resale prices on seat quality and seat quality squared (1 moment). Hence, we use a total of 28 moments to estimate the 13 parameters.

\subsection{Identification}

We now offer an intuitive explanation of how the data identify the model's parameters. The curvature parameter $\phi$ is identified by the shape of the relationship between resale prices and seat quality. The shape of the price-quality relationship also influences the estimates of $\mu_{\omega}$ and $\sigma_{\omega}$, the mean and standard deviation of the distribution of $\log \omega$. However, these parameters are driven primarily by the level of resale prices for the highest-quality tickets: as explained above, a consumer's $\omega$ determines the ratio of her willingness to pay for the best seat vs. the worst seat. If we observe in the data that resale prices for the best seats are typically 3 times more than for the worst seats, then the distribution needs to be such that the highest draws of $\omega$ are around 2 .

The parameter $\mu_{L}$ determines the average number of bidders who randomly participate in each resale auction. In combination with the heterogeneity in willingness to pay (as captured by $\left.\sigma_{\omega}\right)$, this parameter drives our model's prediction of how noisy the relationship between resale prices and seat quality will be. This is the rationale for including the standard deviation of the residuals from a regression of resale prices on seat quality as a moment to be matched in the estimation.

The standard deviation of demand shocks, $\sigma_{\Delta}$, is identified by the frequency with which tickets are resold at a loss. The more often we observe instances where buyers (especially brokers) overestimated demand for an event, the larger will be our estimate of $\sigma_{\Delta}$.

The fraction of buyers who are brokers $(\beta)$ is mainly driven by the relative frequency of sales by brokers in the resale market. To be clear, however, the estimate will not simply equal the relative frequency of broker sales in the data. If consumers have higher transaction costs than brokers, as we expect, then brokers will be more likely than consumers to speculate in the primary market - so even a small $\beta$ could be consistent with a large fraction of resales being done by brokers.

39. The five buckets are (day 1 , days $2-7$, days $7-14$, days $15-30$, days $31+$ ). 
The probability of schedule conflicts, $\psi$, is driven by the relative rate at which consumers versus brokers resell below face value. The model assumes that both types of buyer have the same information, so they should be equally likely to overestimate demand for an event. To the extent that consumers are more likely than brokers to sell at a loss, in the model this must be driven by schedule conflicts (which matter for consumers but are irrelevant for brokers).

Identification of consumers' transaction costs is driven by their relative propensity to resell at high vs. low expected markups. Loosely speaking, positive transaction costs allow the model to rationalize low rates of resale in the data even for tickets that would have fetched very high markups. More specifically, the estimated transaction cost should depend on the slope of the relationship between the probability of resale and the expected markup, and particularly on where that slope becomes positive. For example, suppose that $\tau_{c}$ is equal to $\$ 20$. For tickets that would resell for less than $\$ 20$ above face value, the model will predict very low probabilities of resale by consumers. More importantly, the probability of resale will be independent of the expected markup if that markup is less than \$20. Only as the expected markup rises above $\$ 20$ will the probability of resale increase (i.e. at $\$ 20$ the slope would become positive).

The arrival cost parameters $\left(\mu_{\theta}, \sigma_{\theta}\right.$, and $\left.c_{0}\right)$ are identified by the timing of purchases in the primary market. The data reveal the marginal benefit of accelerating arrival in the primary market. To the extent that resale prices capture the tickets' market value, they also tell us how much more valuable it was to be 1 st in the buyer sequence as opposed to 101st, say. For events that were dramatically underpriced, this difference tends to be large, so we expect buyers to hurry and tickets to sell out very quickly. By contrast, for an event that is not underpriced, the incentives to arrive early are much weaker: only consumers with high willingness to pay for quality (high $\omega)$ have much incentive to hurry to the front of the line. This pattern is indeed what we observe in the data: the events for which the resale margins were the highest were also the events for which primary market tickets sold fastest. Essentially, for any given event the data tell us: (a) how valuable it was to come early; and (b) how quickly the tickets sold (i.e. how hard buyers tried to come early). Observing this relationship across events allows us to back out what the costs of early arrival must be. Naturally, the moments related to the timing of primary market sales are intended to leverage this source of variation.

The estimate of $\delta_{b}$, which represents the degree to which brokers' arrival cost distribution differs from the distribution for consumers, is driven by the difference in the average quality of tickets resold by brokers vs. consumers. In the data, broker resales tend to be for higher-quality tickets, suggesting that they tend to be better than the average non-broker at arriving early in the primary market.

Finally, the correlation between arrival cost types $(\theta)$ and willingness to pay $(\omega)$ is identified by the relative demands for high- vs. low-quality tickets in the early stages of the arrival sequence. Consumers who arrive early in the primary market can typically choose between high-quality, high-price seats and lower-quality, lower-price seats. If early arrivers tend to buy lower-quality seats (e.g. seats in the second price level or lower), this would suggest that $\theta$ and $\omega$ are positively correlated.

Based on this logic we include moments measuring high- vs. low-quality sales in the early portion of the on-sale period. The relevant variation is highlighted in Table 3 which shows how early sales are skewed towards high-quality seats. To control for the fact that top quality ticket sales might be low after the first few days simply because few such tickets remain, we calculated the top quality tier's share of ticket sales for each day and divided by the top quality tier's share of remaining capacity on that day. The pursuit of resale profits might itself skew sales towards high-quality seats, but the pattern is the same if we look only at events with below-median levels of resale activity, as shown in the second column. 
TABLE 3

Early buyers' seat quality purchases

\begin{tabular}{lcc}
\hline & \multicolumn{2}{c}{$\begin{array}{c}\text { (Top tier's share of sales)/ } \\
\text { (Top tier's share of remaining capacity) }\end{array}$} \\
\cline { 2 - 3 } Day & All events & Low-resale events \\
\hline 1 & 1.42 & 1.55 \\
2 & 0.98 & 1.33 \\
3 & 0.93 & 1.15 \\
4 & 0.50 & 0.76 \\
5 & 0.35 & 0.55 \\
6 & 0.62 & 0.22 \\
7 & 0.46 & 0.53 \\
8 & 0.47 & 0.11 \\
9 & 0.20 & 0.18 \\
10 & 0.18 & 0.25 \\
\hline
\end{tabular}

Notes: For each event and for each day (starting from when the tickets first go on sale), we calculate the top quality tier's share of sales and divide by the top quality tier's share of remaining capacity. Values greater than 1 indicate that the highest quality tier had a disproportionate share of sales on that day. Cells report the medians across events.

While the correlation parameter is in principle identified by the data variation described in Table 3 this variation is of course clouded by many other factors that are also included in the model (such as differences in relative prices). This suggests identification of the $\sigma_{\omega \theta}$ parameter may partly rely on functional form assumptions. Note, however, that the overall level of resale activity also helps identify the correlation $\sigma_{\omega \theta}$. In the model, if $\omega$ and $\theta$ are negatively correlated, then the early arrivers also tend to be the buyers with the highest willingness to pay. In that case the primary market allocation is relatively efficient, leading to smaller gains from reallocation and fewer resales. If instead $\omega$ and $\theta$ are positively correlated, then the primary market allocation is very inefficient and (all else equal) we would expect to see a high volume of resale activity as tickets are traded from low- $\omega$ consumers to high- $\omega$ consumers. Hence, the estimate of $\sigma_{\omega \theta}$ must fit the observed level of resale activity, in addition to the patterns shown in Table 3

\subsection{Estimation results}

The estimates are reported in Table 4 We estimate that consumers' willingness-to-pay and arrival cost parameters $(\omega$ and $\theta$ ) are negatively correlated. Thus, consumers who value the tickets highly will also tend to come earlier in the primary market buyer sequence. An implication is that the primary market allocation will be somewhat more efficient than a random allocation. We examine this issue more closely in the next section. The estimated distribution of $\omega$ is such that the average consumer is willing to pay 1.7 times more for the best seat than she is for the worst seat. A consumer at the 90th percentile of the distribution would be willing to pay about 2.6 times more.

The mean of the arrival cost distribution for brokers is estimated to be 0.27 times the mean for non-brokers, suggesting that brokers have significantly better technologies for arriving early in the primary market. The estimated fraction of brokers $(\beta)$ is 0.015 , implying that there is one broker for every 67 consumers. Note that while brokers are a small fraction of buyers, they account for a larger fraction of resale activity. In the simulations we report below, 47 percent of resold tickets come from brokers.

The parameters of the arrival cost distribution imply that if no effort were exerted in the arrival game, about $55 \%$ of the buyers would arrive in the first week of the onsale period. To arrive on the first day, a consumer at the 50th percentile of the distribution of $\theta$ would incur costs of roughly $\$ 23$, while a consumer at the 90th percentile would incur the same cost to arrive on day 6 . 
TABLE 4

Estimated parameters

\begin{tabular}{llrc}
\hline Parameter & Notation & Estimate & Std. Error \\
\hline Consumers' transaction cost & $\tau^{c}$ & 57.031 & 0.581 \\
Curvature & $\phi$ & 1.010 & 0.025 \\
Mean of willingness to pay & $\mu_{\omega}$ & -1.016 & 0.029 \\
SD of willingness to pay & $\sigma_{\omega}$ & 1.164 & 0.020 \\
Mean of arrival cost & $\mu_{\theta}$ & 1.748 & 0.007 \\
SD of arrival cost & $\sigma_{\theta}$ & 1.432 & 0.008 \\
Correlation of WTP, arrival cost & $\sigma_{\omega \theta} / \sigma_{\omega} \sigma_{\theta}$ & -0.376 & 0.004 \\
Scale for brokers' arrival costs & $\delta_{b}$ & 0.267 & 0.009 \\
Prob(conflict) & $\psi$ & 0.054 & 0.001 \\
Prob(broker) & $\beta$ & 0.015 & 0.0002 \\
Parameter of arrival cost function & $c_{0}$ & 1.011 & 0.031 \\
Number of bidders in resale auctions & $\mu_{L}$ & 1.448 & 0.101 \\
SD of event-specific demand shock & $\sigma_{\Delta}$ & 0.804 & 0.007 \\
\hline
\end{tabular}

Consumers' transaction costs are estimated to be about $\$ 57$. This may be because many consumers have never used eBay before and perceive there to be significant setup costs involved in doing so for the first time. Another interpretation is that the transaction cost captures an endowment effect (see Kahneman et al., 1990), such that consumers' valuations of tickets increase after purchasing them 40

The estimate of $\mu_{L}$ implies that resale auctions have on average only 2.4 buyers participating, and that $90 \%$ of auctions have between 1 and 6 bidders. This estimate is driven by the relatively high variance of resale prices (conditional on seat quality) that we observe in the data. The number also matches the data reasonably well: for eBay auctions, the average number of submitted bids was 3.8 (unconditional on whether the auction ended with a sale), and the number of unique bidders is generally lower than the number of submitted bids (since some bidders submit more than one bid) 41

In general, the model fits the resale-related moments fairly well. The percentiles of the resale price and quality distributions are matched very closely, especially in the upper tails. The model does a worse job predicting primary market sales, underpredicting the fraction of tickets sold by an average of more than ten percentage points. The fraction of tickets resold is slightly overpredicted by the model. We suspect the model would achieve a significantly better fit of the primary market moments if it were computationally tractable to estimate event fixed effects (i.e. the $\alpha_{k}$ 's) directly.

\section{COUNTERFACTUAL ANALYSES}

We now turn to our primary objective of quantifying the resale market's impact on aggregate social welfare and the distribution of surplus among primary market sellers, brokers, and consumers. We do this by means of counterfactual analyses: i.e. given our estimates of the structural parameters, as reported in Table 4 we simulate market outcomes under various hypothetical changes to the market environment.

The two-step approach used to estimate the model is not suitable for simulating counterfactuals, since it estimates buyers' expectations from the data and then holds those

40. Krueger (2001) argues that endowment effects are in fact important in ticket markets.

41. If some bidders "participate" without bidding, then the number of bids is not an upper bound for the number of participants. Also, the average number of bids is higher if we condition on auctions that ended with a sale. But the number relevant to our estimate is the unconditional average. 
expectations fixed. However, changes to the market environment change buyers' decisions in the primary market and their expectations about the secondary market. Indeed, some of the changes we consider will affect market outcomes only insofar as they affect buyers' expectations about the secondary market. Therefore, in our simulations we employ a computational algorithm to find rational expectations equilibria in which (i) brokers and consumers make decisions optimally in the arrival and primary market stages, given their expectations about payoffs in the final stage (the resale market); and (ii) those expectations are on average correct, given optimal decisionmaking in the arrival game and primary market. The details of this algorithm are described in Appendix A. In essence, we begin with a parameterized approximation to the buyer's value function - the function describing her expected final payoff as a function of her $\omega$ and the ticket she is holding from the primary market. We then iterate on the parameters of this function until we find a fixed point: a value function that leads to arrival times and primary market decisions that in turn generate resale market outcomes consistent with the expectations embodied in the value function.

In order to quantify how resale affects primary market sellers, we focus on how resale affects their revenues. As we discussed above, the motivation behind the observed pricing practices (i.e. the primary market sellers' true objective function) is unclear. Regardless, ticket revenues are surely an important component of their objective, and with our counterfactuals we can compute how much revenue is forgone to pursue whatever other objectives the artists may have in mind. We also discuss below how our conclusions about the welfare effects of resale would differ if artists care about the surplus of the concert attendees. It is also important to note that we do not reoptimize primary market prices in each experiment 42 If we were to re-optimize prices we would also need to determine the number and size of price tiers (which could be treated endogenously or exogenously), and none of this would solve the problem that we may not have the right objective function.

Table 5 compares outcomes under varying levels of resale frictions. To construct the table, we calculate averages across 100 simulated outcomes for each event, and then report averages across 55 events 43 For the "base case" we simulate the model at the estimated parameter values. Outcomes in the "no resale" case are simulated by setting the transaction costs $\left(\tau_{b}\right.$ and $\left.\tau_{c}\right)$ to arbitrarily high levels. To simulate outcomes with "frictionless resale", we set transaction costs to zero and increase the number of participants in the resale auctions to include all potential buyers 44

\subsection{Welfare consequences of resale}

The first three columns of Table 5 are based on the estimated model with an endogenous arrival sequence of buyers in the primary market. In the top row we report the gross surplus of the consumers who attend the event. The principal consequence of resale markets is to reallocate products to consumers with higher willingness to pay, and changes in the gross surplus of attendees capture the efficiency gains from this reallocation. To facilitate comparisons across regimes, we normalize all numbers in the table so that gross surplus equals 100 in the no resale case. There is no ex ante ambiguity about the effect of resale on gross surplus of attendees-resale helps

42. There is one exception to this, in which we re-price the best $10 \%$ of seats (as explained below).

43. For the counterfactual analyses we omitted one event for which the model provides a poor fit.

44. It would be more precise to call this case "almost frictionless". By eliminating transaction costs and including all potential buyers in every resale auction, we remove the frictions that operate within our model. But the final allocation will not be one with assortative matching, because we do not allow ticketholders to sell and then buy (i.e. "trade up") in the resale market. 
TABLE 5

Counterfactual simulations: no resale vs. frictionless resale

\begin{tabular}{|c|c|c|c|c|c|}
\hline & \multicolumn{3}{|c|}{ Endogenous arrival } & \multicolumn{2}{|c|}{ Random arrival } \\
\hline & No resale & Base case & Frictionless & No resale & Frictionless \\
\hline Gross surplus of attendees & 100.0 & 104.1 & 109.4 & 83.0 & 106.6 \\
\hline Transactions costs incurred & 0.0 & 1.0 & 0.0 & 0.0 & 0.0 \\
\hline Arrival costs incurred & 5.1 & 5.4 & 7.8 & 0.0 & 0.0 \\
\hline Net surplus & 94.9 & 97.7 & 101.5 & 83.0 & 106.6 \\
\hline Primary market revenues & 60.3 & 64.7 & 65.1 & 62.0 & 66.3 \\
\hline \multicolumn{6}{|l|}{ Resellers' profits: } \\
\hline Brokers & 0.0 & 0.4 & 0.4 & 0.0 & 0.7 \\
\hline Non-brokers & -2.4 & -3.1 & 11.4 & 0.0 & 25.0 \\
\hline Attendees' net surplus & 37.0 & 36.3 & 25.0 & 21.0 & 14.9 \\
\hline
\end{tabular}

Notes: Numbers represent averages across events, with 100 model simulations for each event. Numbers are normalized so that attendees' gross surplus equals 100 in the "no resale" case with endogenous arrival. For the "base case" column, the model is simulated at the estimated parameters. The "no resale" column reflects outcomes when transactions costs are set arbitrarily high; the "frictionless" case reflects outcomes when transactions costs are set to zero and the number of bidders in the secondary market auctions is set to 600 . The "endogenous arrival" columns correspond to the model we estimate, in which buyers make strategic arrival decisions in the primary market. In the "random allocation" columns, we simply assign the buyer sequence randomly (and independently of buyers' willingness to pay).

tickets end up in the hands of high value consumers. In terms of magnitude, we find that the actual level of resale in the data results in $4.1 \%$ higher gross surplus than if there was no resale. Under frictionless resale, gross surplus is $9.4 \%$ higher than the no resale case. Although not shown in the table, under frictionless resale $46 \%$ of tickets sold in the primary market are resold (on average).

However, a key point of our study is that there are costs associated with achieving this improvement in allocative efficiency. In the base case we find that the combination of transaction costs in the resale market and increased costs of effort in the arrival game amounts to over $33 \%$ of the gross surplus gain. Hence, while gross surplus increases by $4.1 \%$, net surplus increases by only $2.9 \%$ (under the base case relative to no resale). Notice also that under the base case arrival costs increase by a only a small amount relative to the no resale scenario. Most of the increase in cost stems from transaction costs in the resale market. By comparison, in the frictionless resale regime we find that arrival costs significantly increase, because the possibility of costless resale increases buyers' incentives to compete for the best tickets. Under purely frictionless resale, everyone values the best seat at the willingness-to-pay of the highest- $\omega$ consumer (as described in the simple numerical example presented in Section 4.2.

We noted above that the increased costs associated with resale could more than offset the improvement in allocative efficiency. While this is not the case on average for our estimated model, our simulations indicate that for some events net surplus would increase if resale were eliminated. That is, while gross surplus is always higher in the base case versus the no-resale case, for some events this increase is outweighed by the combination of transaction costs and increased arrival costs in the base case. At observed levels of resale activity, therefore, the impact of resale on net social surplus may be positive on average, but it is a close call. By contrast, we find no ambiguity in the frictionless resale case: relative to no resale, we estimate that frictionless resale would increase net surplus for all events in our sample.

The bottom panel of the table shows how the surplus is divided among the various market participants. Notably, we find that resale significantly reduces the net surplus of event attendees. Under the base case, attendees' net surplus is $2 \%$ lower than the no resale case. Under frictionless resale attendees are $32 \%$ worse off. The table also shows that non-broker resellers (consumers that 
resell tickets) are the biggest winners. This suggests that consumers overall benefit from resale, even though consumer attendees are harmed 45 However, it is important to realize that our model does not allow for an endogenous increase in the number of brokers as the profitability of resale increases. Hence, a better interpretation is that resellers as an aggregate category are the main beneficiaries. In other words, in this analysis it is more meaningful to look at the value captured by resellers in aggregate than it is to make a distinction between brokers and non-brokers 46 Regardless, the main point is that, in a world with frictionless resale, consumers get the "right" tickets, but they pay a much higher price for them.

Many of the proposed rationalizations for underpricing in the primary market, such as concerns about fairness or about building a fan base, imply that artists care not just about their own revenues, but also about the net surplus earned by their concertgoers. Suppose we assume that the artist objective function is a weighted sum of own revenues and attendees' net surplus. The numbers in Table 5 imply that if artists put $40 \%$ weight on attendees' net surplus and $60 \%$ weight on their own revenues, then the no-resale regime would yield higher total welfare than the frictionless resale regime.

\subsection{Importance of endogenous arrival}

A central tenet of this study is that it is essential to model the impact of resale on primary market behaviour, in order to fully assess the consequences of resale activity. In particular, the efforts of buyers to obtain tickets in the primary market - which determine the allocation of tickets in the primary market - depend on whether resale is possible. In the last two columns of Table 5 we show how different our conclusions would be if we instead assumed that buyers arrive in a purely random sequence (regardless of whether resale is possible). That is, instead of allowing buyers to choose their arrival strategically, we simply assign the sequence randomly in a way that is independent of willingness to pay.

Without resale, a purely random buyer sequence leads to an allocation that is $17 \%$ less efficient than the allocation that results from endogenous arrival (comparing columns 1 and 4). This is because endogenous primary market allocations are significantly more efficient than random allocations: high-value buyers tend to invest in early arrival. Importantly, this also means that if we had estimated the model without endogenizing the arrival sequence, we would have dramatically overstated the potential gains from reallocation through resale. Under random arrival, frictionless resale leads to a massive increase in net surplus from 83.0 to 106.6 - an increase of $28 \%$ (compared to $7 \%$ under the model with endogenous arrival) 47

\subsection{Strategic interaction in arrival game}

Effort choices in the arrival game are strategic decisions because the position of any individual in the arrival sequence depends on the effort levels of other buyers (in addition to their own effort). Figure 5 graphically shows the strategic effect that resale has on arrival costs, based on the estimated model. On the horizontal axis are the deciles of the marginal (estimated) distribution

45. The table implies that frictionless resale leads to a 5\% increase in total consumer surplus, but a $28 \%$ decrease in surplus of consumers that actually attend the event.

46. In practice, we fully expect that any increase in profitability of resale will increase broker participation, and we suspect that brokers would in fact be the main beneficiaries of frictionless resale.

47. Note that if resale were literally frictionless, then the gross surplus of attendees would be equal in columns 3 and 5 of the table. However, buyers' inability to trade up in the resale market means that the final allocation still depends to some extent on the order of arrivals in the primary market. 


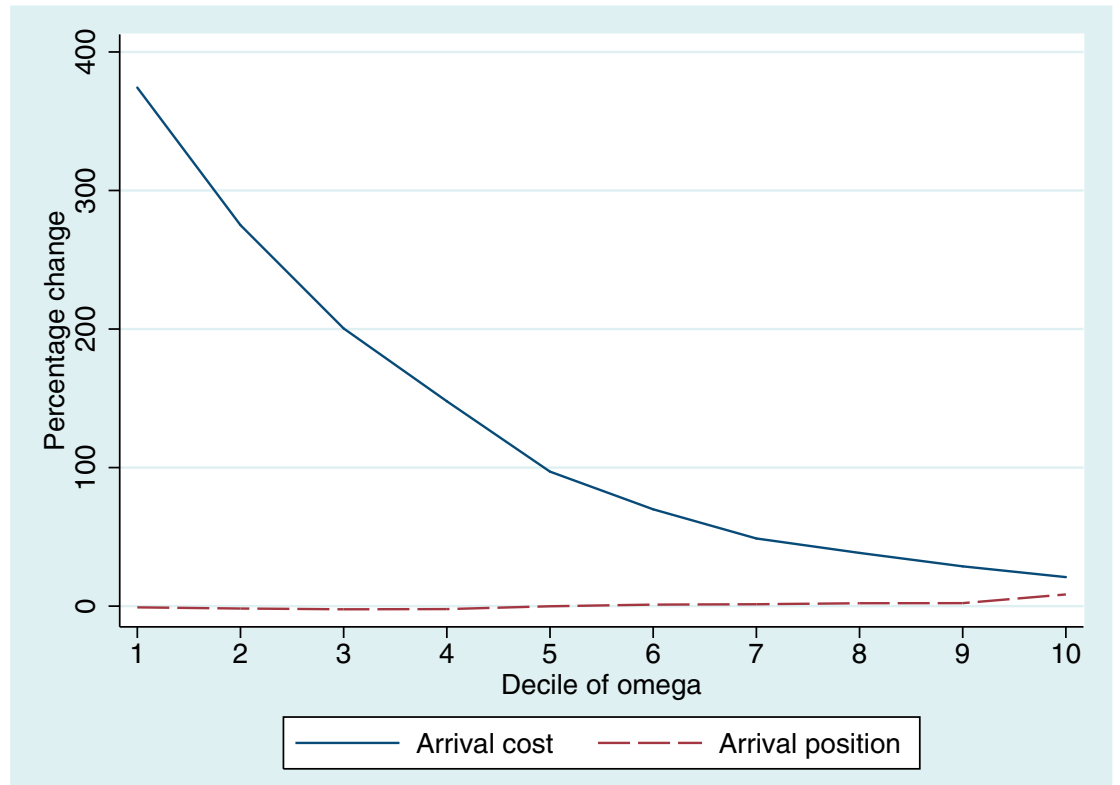

FIGURE 5

The impact of resale on arrival costs, by willingness-to-pay $(\omega)$. Percentage changes in average arrival cost incurred (solid line) and average arrival position (dashed line), by decile of willingness-to-pay ( $\omega$ ), when we move from a world without resale to a world with frictionless resale. For example, the average arrival costs of buyers with $\omega$ 's in the lowest decile increase by almost $400 \%$ under frictionless resale, but their average arrival position is essentially unaffected.

of consumers' willingness to pay for seat quality $(\omega)$. The solid line represents the percent change in average arrival cost for each decile of consumers, due to a change from no resale to frictionless resale. The dashed line indicates the percent change in average position in the arrival sequence, for each decile.

It is evident from Figure 5 that low- $\omega$ consumers dramatically increase their arrival costs when resale is allowed, for the reasons explained above. Of greater interest is the fact that average arrival costs also increase for high- $\omega$ types. On the one hand, resale may cause some high- $\omega$ consumers to reduce their effort in the arrival game, preferring instead to let others incur those costs, and knowing that they have the option of waiting to buy a ticket in the resale market. On the other hand, if they do wish to purchase a ticket in the primary market-preferably an underpriced, high-quality ticket - then the high- $\omega$ types will need to increase their arrival efforts as a strategic response to the higher efforts of the low- $\omega$ types. The figure indicates that the latter effect tends to outweigh the former.

The dashed line in Figure 5 shows that the (sometimes dramatic) increase in arrival effort results in barely any change in the arrival sequence. Recall that we estimate a negative correlation between $\omega$ and $\theta$ : high-value consumers tend to have a low cost of effort. Combined with high- $\omega$ types' stronger incentives to obtain the best tickets, this leads to a no-resale equilibrium in which high- $\omega$ consumers tend to be early in the arrival sequence. As shown in the figure, frictionless resale causes these same consumers to increase their efforts in order to preserve their early position, futher illustrating the importance of strategic interaction in the arrival game. 
TABLE 6

Counterfactual simulations: the impact of brokers

\begin{tabular}{lccc}
\hline & $\begin{array}{c}\text { No brokers } \\
(\beta=0)\end{array}$ & $\begin{array}{c}\text { Base case } \\
(\beta=0.015)\end{array}$ & $\begin{array}{c}\text { More brokers } \\
(\beta=0.03)\end{array}$ \\
\hline Gross surplus of attendees & 96.8 & 100.0 & 100.3 \\
Transactions costs incurred & 0.9 & 1.0 & 1.0 \\
Arrival costs incurred & 5.1 & 5.2 & 5.1 \\
Net surplus & 90.7 & 93.8 & 94.2 \\
Primary market revenues & 58.9 & 62.1 & 63.1 \\
Resellers' profits: & 0.0 & 0.4 & 0.7 \\
$\quad$ Brokers & -3.1 & -3.0 & -2.9 \\
$\quad$ Non-brokers & 34.9 & 34.8 & 34.4 \\
\hline
\end{tabular}

Notes: Numbers represent averages across events, with 100 model simulations for each event. Numbers are normalized so that attendees' gross surplus equals 100 in the "no brokers" case.

\subsection{Role of brokers}

Many legal restrictions on ticket resale seem to be motivated by hostility towards brokers. In Table 6 we explore counterfactuals that vary the level of broker participation. The first column reports results from simulating the model with $\beta$ (share of buyers who are brokers) set to zero. In the second column $\beta$ is set to its estimated value of 0.015 , and in the last column we double the fraction of brokers to $\beta=0.03$. We normalize all values in the table based on the gross surplus under the base case (set to 100).

As the table shows, increasing the presence of brokers leads to higher levels of gross surplusi.e. more efficient allocations - because brokers provide liquidity to the resale market. Net surplus increases as well, because we estimate that brokers have low transactions costs and relatively low arrival costs, so the improvement in allocative efficiency comes at little additional cost. In our simulations, brokers capture less than $20 \%$ of the value that they create. Attendees are made slightly worse off by broker activity, since brokers purchase some of the primary market tickets and resell them at higher prices. Primary market sellers are made significantly better off. Since we do not allow sellers to re-optimize prices in our simulations, this reflects a pure quantity effect: increasing the presence of brokers leads to more primary market sales on average.

As above, we can ask whether the welfare implications of our analysis would change if artists value the surplus of concert attendees. In this case, the increases in primary market revenue that result from increasing broker participation are much larger than the corresponding declines in attendees' surplus. So artists would have to care almost exclusively about attendees' net surplus in order for broker participation to be undesirable from a social welfare standpoint.

\subsection{Re-pricing best seats}

Much of the observed resale activity in our data appears to be driven by unpriced seat quality. In particular, consumers evidently are willing to pay significant price premiums for the very best seats, but these seats are typically sold together with many inferior seats at the same coarsely defined price level. To understand what would happen to resale activity if the best seats were re-priced, we simulated a counterfactual in which we took the top $10 \%$ of each event's seats and assigned them a new price equal to the median observed resale price for those seats. Hence, under this counterfactual we add one additional price level to every event.

We find that the average increase in primary market revenue is $3.4 \%$ (an average of approximately $\$ 27,000$ per event). This number is similar to the finding of Courty and Pagliero 
(2010) that price discrimination (i.e. using multiple price levels) at major rock concerts increases revenue by an average of 5\%. Since the price change we considered was a relatively crude one, this difference is a lower bound for how much money producers are leaving on the table by not scaling the house more finely 48 The more striking result from this simulation was that setting higher prices for premium tickets significantly weakens buyers' incentives to invest in early arrival. Relative to the baseline model, arrival costs declined by $9 \%$.

These results reinforce an important point. In policy debates about resale markets, opponents of resale tend to blame brokers for the difficulty that consumers face in obtaining tickets (which we interpret as increased effort costs in the primary market). However, if primary market sellers were to implement more sophisticated pricing policies, our results indicate that consumers' arrival costs would decline significantly. Eliminating or discouraging brokers my lessen the competition for tickets in the primary market, but a more direct way to mitigate wasteful rent-seeking would be through improvements in primary market pricing.

\section{CONCLUSION}

A common complaint from consumers is that resale markets make it more difficult to obtain tickets in the primary market. However, before the internet boosted ticket reselling (by lowering resale transaction costs), consumers complained about the difficulty of purchasing tickets to popular events at all. Our modelling approach captures both of these effects. Resale stimulates competition for tickets in the primary market, making it costlier (in an effort sense) to buy in the primary market. But resale also makes it easier for consumers to buy tickets to any event in the resale market, as long as they are willing to pay market-driven prices. In other words, resale exacerbates the problems associated with excess demand in the primary market (i.e. costly rent-seeking behaviour), but makes the final allocation of goods to consumers more efficient. This article has sought to clarify these effects and empirically quantify their magnitudes.

Our approach has focused on the interdependence of primary and secondary markets, and is the first (to our knowledge) to analyse data from both markets in parallel. Our findings show that while the basic economics of resale markets are simple (buy low, sell high), the welfare consequences of resale - in particular, the distribution of gains and losses-are more subtle. In the market for rock concerts, we find that observed levels of resale activity generate modest welfare gains relative to a world without resale. However, substantial increases in social surplus could be realized by eliminating or reducing frictions in the resale market (e.g. transaction costs). To the extent that online marketplaces like StubHub facilitate secondary market exchanges by lowering transaction costs, we can infer that their services increase the total surplus generated by the market for event tickets.

Resale leads to a more efficient allocation of tickets, but does so at a cost. By enabling profitable resale transactions, it motivates individuals to engage in costly rent-seeking behaviour in the primary market. Our analysis emphasizes how strategic interactions amplify these costs. We find that these costs are substantial. Comparing the observed level of resale to a counterfactual world with no resale, one third of the gain in gross surplus from reallocation is offset by increased arrival and transaction costs.

In the USA, recent advances in paperless/digital ticketing technologies have made it possible for sellers to prevent resale if they so choose. This has shifted the policy debate from whether

48. Alternatively, if the actual objective of the primary market seller is something other than primary market ticket revenues, then this experiment provides a lower bound on how much ticket revenue is forgone in order to pursue this other objective (e.g. merchandise sales). 
resale should be allowed to whether resale should be protected 49 Our results suggest that resale markets are in fact welfare-improving: on average, resale creates gains in allocative efficiency that outweigh the additional transaction and rent-seeking costs. Thus, if the aim of public policy is to maximize total surplus (as arguably it should be), then our findings provide some support for the repeal of anti-scalping laws and for the protection of consumers' rights to resell or transfer their tickets.

Not everyone benefits from resale, however. In particular, consumers who attend the event may be worse off when resale markets become more fluid. Seats are allocated more efficiently, but the additional surplus generated by the improved allocation is mostly captured by resellers. As a group, concert attendees would have preferred less efficiently allocated tickets obtained at lower prices. We find that frictionless resale markets would lower the surplus of concert attendees by $17 \%$ on average. From a consumer protection standpoint, therefore, the policy implications of our analysis may be different: if the narrow goal is to maximize the surplus of those who ultimately attend the event, then restrictions on resale may be warranted.

\section{Appendix A}

This appendix describes how we find rational expectations equilibria when performing the counterfactual simulations described in Section 7. Given the structure of payoffs in the model, a rational expectations equilibrium is one in which: (i) brokers and consumers make decisions optimally in the arrival and primary market stages given their expectations about payoffs in the final stage (the resale market); and (ii) those expectations are on average correct given optimal decision-making in the arrival game and primary market 50 The challenge is finding expectations that rationalize a set of arrival times and primary market decisions that in turn lead to resale market outcomes consistent (on average) with those expectations. In other words, the trick is to find a fixed point in the mapping of expectations into average resale market outcomes.

Buyers' expecations cannot be calculated analytically, even for particular assumptions about the probability distributions of the various sources of uncertainty. We therefore take a computational approach that is similar in spirit to Rust's (2000) “parametric policy iteration". We conjecture a parameterized approximation to the buyers' expected values, and then iterate on the parameters of that approximation until we converge to a fixed point. We do this separately for expectations at the arrival game stage and the primary market stage, since the information set is slightly different at each of these stages. In particular, buyers in the arrival game are uncertain about which seats they will be able to buy in the primary market, because they cannot anticipate the exact purchase decisions of buyers who come ahead of them in the sequence. At the primary market stage, however, buyers know exactly which seats are available, and the only remaining uncertainty is about resale market outcomes.

Consider first the primary market stage. A buyer's expected utility, as a function of the primary market choice, depends on: (i) whether the buyer is a broker or consumer; (ii) the quality ( $v$ ) of the ticket purchased, if any; and (iii) the buyer's $\omega$ if the buyer is a consumer. We therefore choose a parametric function $V_{1}\left(b, v, \omega \mid \gamma_{1}\right)$ to represent buyers' expectations at the primary market stage, where $b$ is an indicator for whether the buyer is a broker, and $\gamma_{1}$ are the parameters.

The algorithm for finding a fixed point is as follows:

1. Choose an initial set of parameters, $\gamma_{1}^{0}$. Simulate primary and secondary market outcomes for $S$ draws on the model's random variables (arrival sequences, schedule conflicts, etc.), where consumers make primary market choices to maximize $V_{1}\left(b, v, \omega \mid \gamma_{1}^{0}\right)$.

2. Use the realized final utilities from the simulations in step 1 to re-estimate the function $V_{1}\left(b, v, \omega \mid \gamma_{1}\right)$. Essentially, we regress realized utilities on a function of $b, v$, and $\omega$ to obtain a new set of parameters, $\gamma_{1}^{1}$.

3. Use the new set of parameters from step 2 to simulate primary and secondary market outcomes as in step 1 . Iterate on steps 1 and 2 until $V_{1}$ converges-i.e. until $V_{1}\left(b, v, \omega \mid \gamma_{1}^{n}\right)$ is sufficiently close to $V_{1}\left(b, v, \omega \mid \gamma_{1}^{n-1}\right)$.

49. Most notably, in 2011 New York state passed a law that requires transferable paper tickets to be an option for consumers whenever restrictive paperless tickets are sold.

50. Forward looking consumer behaviour with rational expectations of future market outcomes is also essential in recent papers by Gowrisankaran and Rysman (2011), and Hartmann and Nair (2010). See also Chevalier and Goolsbee (2009). 
In the simulations of Section 7, we use a very simple parameterization of $V_{1}$. Letting $h$ be an indicator for whether the buyer holds a ticket going into the second period, we let

$$
\begin{aligned}
V_{1}\left(b, \nu, \omega \mid \gamma_{1}\right)= & b \cdot h \cdot\left(\gamma_{10}+\gamma_{11} v\right)+(1-b) \cdot h \cdot\left(\gamma_{12}+\gamma_{13} v+\gamma_{14} \omega+\gamma_{15} v \omega\right) \\
& +(1-b) \cdot(1-h) \cdot\left(\gamma_{16}+\gamma_{17} \omega\right) .
\end{aligned}
$$

This parameterization captures the essential elements of the expectations described above. For a broker, expected utility depends only on the quality of the ticket owned, $v$. For a consumer without a ticket, expected utility depends only on the consumer's willingness to pay for quality, $\omega$. For a consumer holding a ticket, expected utility depends on both $v$ and $\omega$, since ultimately the ticket will either be consumed (yielding a payoff that depends on $v$ and $\omega$ ) or resold (yielding a payoff that depends on $v$ ).

Convergence of this algorithm means we have found a set of expectations $V_{1}$ such that the primary market choices that follow from $V_{1}$ lead to secondary market outcomes consistent with $V_{1}$. The convergence criterion we use is based on average differences in $V_{1}$. At each iteration of the algorithm, we essentially estimate the regression described in equation A.1 using $M \times S$ "observations." We stop iterating when

$$
\frac{1}{M S} \sum_{i=1}^{M S}\left(\frac{\left|V_{1 i}\left(\gamma_{1}^{n}\right)-V_{1 i}\left(\gamma_{1}^{n-1}\right)\right|}{V_{1 i}\left(\gamma_{1}^{n-1}\right)}\right) \leq 0.005 .
$$

In other words, we stop when the fitted values of $V_{1}$ differ from those of the previous iteration by less than half of one percent on average.

At the arrival game stage, buyers' expectations about final payoffs are not a function of $v$, because there is uncertainty about the seat qualities that will remain at the buyer's turn in the sequence. We therefore approximate expectations as $V_{0}\left(z, b, \omega \mid \gamma_{0}\right)$, and use an iterative procedure analogous to the one described above to find a fixed point for $V_{0}$. Namely, we begin with a conjectured set of parameters $\gamma_{0}$, solve the arrival game given the implied $V_{0}$, determine primary and secondary market outcomes given the resulting arrival sequence (including finding a fixed point for primary market expectations $V_{1}$ ), and then regress the final payoffs on a simple function of $z$ (relative arrival position), $b$ (a broker dummy), and $\omega$ (the buyer's willingness-to-pay parameter) to obtain a new estimate of $\gamma_{0}$. We iterate until the fitted values of $V_{0}$ differ from those of the previous iteration by less than half of one percent on average.

The specific parameterization we use for $V_{0}$ is

$$
V_{0}\left(z, b, \omega \mid \gamma_{0}\right)=b\left(\gamma_{00}+\gamma_{01} z+\gamma_{02} z^{2}\right)+(1-b)\left(\gamma_{03}+\gamma_{04} \omega+\gamma_{05} z+\gamma_{06} z^{2}+\gamma_{05} \omega z\right)
$$

Acknowledgments. Thanks to Lanier Benkard, Glenn Ellison, Brett Gordon, and Marc Rysman for valuable suggestions. We are also grateful to Ticketmaster and StubHub for providing data, and to Amitay Alter, Anna Mastri, and Tim Telleen-Lawton for many hours of outstanding research assistance. A prior version of this paper was titled "The Welfare Effects of Ticket Resale".

\section{REFERENCES}

AKERLOF, G. (1970), “The Market for Lemons: Qualitative Uncertainty and the Market Mechanism”, Quarterly Journal of Economics, 84, 488-500.

BECKER, G.S. (1991), “A Note on Restaurant Pricing and Other Examples of Social Influences on Price”, Journal of Political Economy, 99, 1109-116.

BUSCH, L.A. and CURRY, P. (2005), "Rock Concert Pricing and Anti-Scalping Laws: Selling to an Input" (Mimeo).

CHE, Y.-K., GALE, I. and KIM, J. (2013), “Assigning Resources to Budget-constrained Agents", Review of Economic Studies, doi:10.1093/restud/rds025.

CHAVALIER, J.A. and GOOLSBEE, A. (2009), "Are Durable Goods Consumers Forward Looking? Evidence from College Textbooks", Quarterly Journal of Economics, 124, 1853-1884.

CHU, S., LESLIE, P. and SORENSEN, A. (2011), "Bundle-Size Pricing as an Approximation to Mixed Bundling", American Economic Review, 101, 263-303.

CONNOLLY, M. and KRUEGER, A.B. (2006), "Rockonomics: The Economics of Popular Music" (North Holland, Handbook of the Economics and Culture).

COURTY, P. (2003), “Ticket Pricing Under Demand Uncertainty”, Journal of Law and Economics, 46, 627-652.

COURTY, P. and PAGLIERO, M. (2012), "The Impact of Price Discrimination on Revenue: Evidence from the Concert Industry", Review of Economics and Statistics, 94, 359-369.

CRAWFORD, V.P. and KNOWER, E.M. (1981), "Job Matching with Heterogeneous Firms and Workers", Econometrica, 49, 437-450.

DEPKEN, C.A. (2007), "Another Look at Anti-Scalping Laws: Theory and Evidence", Public Choice, 130, 55-77.

DE SERPA, A.C. and R.L. FAITH (1996), "Bru-u-u-uce: The Simple Economics of Mob Goods", Public Choice, 89, 77-91. 
ELFENBEIN, D. (2005), "Do Anti-Scalping Laws Make a Difference Online? Evidence from Internet Sales of NFL Tickets", (Mimeo, Washington University in St. Louis).

GARRATT, R. and TRÖGER, T. (2006), "Speculation in Standard Auctions with Resale", Econometrica, 74, 753-769. GENG, X., WU, R. and WHINSTON, A.B. (2007), "Profiting from Partial Allowance of Ticket Resale", Journal of Marketing, 71, 184-195.

GOWRISANKARAN, G. and RYSMAN, M. (2011), "Dynamics of Consumer Demand for New Durable Goods" (Mimeo).

HAFALIR, I. and KRISHNA, V. (2008), "Asymmetric Auctions with Resale", American Economic Review, 98, 87-112.

HAILE, P. (2001), "Auctions with Resale Markets: An Application to U.S. Forest Service Timber Sales", American Economic Review, 91, 399-427.

HAILE, P. (2003), “Auctions with Private Uncertainty and Resale Opportunities", Journal of Economic Theory, 108, $72-110$.

HAPPEL, S.K. and JENNINGS, M.M. (1995), “The Folly of Antiscalping Laws”, The Cato Journal, Spring.

HARTMANN, W.R. and Nair, H.S. (2010), "Retail Competition and the Dynamics of Consumer Demand for Tied Goods", Marketing Science, 29, 366-386.

HASSETT, K.A. (2008), "Estimating the Consumer Benefits of Online Trading" (Mimeo).

HENDEL, I. and LIZZERI, A. (1999), "Interfering with Secondary Markets", RAND Journal of Economics, 30, 1-21.

KARP, L. and PERLOFF, J. (2005), "When Promoters Like Scalpers", Journal of Economics and Management Strategy, 14, 477-508.

KAHNEMAN, D., KNETSCH, J. and THALER, R. (1986): "Fairness as a Constraint on Profit Seeking: Entitlements in the Market", American Economic Review, 76, 728-741.

KAHNEMAN, D., KNETSCH, J. and THALER, R. (1990), "Experimental Tests of the Endowment Effect and the Coase Theorem", Journal of Political Economy, 98, 1325-1348.

KRUEGER, A.B. (2001), "Supply and Demand: An Economist Goes to the Super Bowl", Milken Institute Review: A Journal of Economic Policy, 3, 22-29.

LESLIE, P. (2004), "Price Discrimination in Broadway Theatre", RAND Journal of Economics, 35, 520-541.

MCCLOSKEY, D. (1985), The Applied Theory of Price, 2nd edn. (New York: McMillan).

MANKIW, G.N. (2007), Principles of Microeconomics, 4th edn. (Thoms South-Western).

MORTIMER, J. and CONLON, C. (2007), "Demand Estimation Under Incomplete Product Availability" (Mimeo).

MULPURU, S. and HULT, P. (2008), The Future of Online Secondary Ticketing (Forrester Research Inc).

ROSEN, S. and ROSENFIELD, A. (1997), "Ticket Pricing”, Journal of Law and Economics, 40, 351-376.

ROTH, A.E. (2007), "Repugnance as a Constraint on Markets", Journal of Economic Perspectives, 21, 37-58.

RUST, J. (2000), "Parametric Policy Iteration: An Efficient Algorithm for Solving Multidimensional DP Problems?" (Mimeo, Yale University).

SHAPLEY, L. S. and Shubik, M. (1972), “The Assignment Game I: The Core”, International Journal of Game Theory, 1, 111-130.

SWEETING, A. (2012), "Price Dynamics in Perishable Goods Markets: The Case of Secondary Markets for Major League Baseball Tickets", Journal of Political Economy, 120, 1133-1172.

THIEL, S. (1993), “Two Cheers for Touts”, Scottish Journal of Political Economy, 40, 447-455.

WILliAMS, A. (1994), “Do Anti-Ticket Scalping Laws Make a Difference?” Managerial and Decision Economics, 15, 503-09.

YATCHEW, A. (1997), “An Elementary Estimator of the Partial Linear Model”, Economics Letters, 57, $135-143$. 